\title{
Tractat de medicina per tots els ocells de caça. Introducció, anàlisi lèxica i edició
}

\section{The Treatise on medicine for all hunting birds. Introduction, lèxical analysis and edition}

\author{
Antoni Mas i Miralles \\ antoni.mas@ua.es \\ Universitat d'Alacant
}

Institut Interuniversitari de Filologia Valenciana

\begin{abstract}
Resum: Aquest treball ofereix l'edició d'un tractat de falconeria, anònim, escrit en català i que, segurament, el podem datar en el segle XV. El manuscrit 102 que es conserva a la Biblioteca de la Universitat de Barcelona conté dos textos; en primer lloc, una traducció feta per Antoni Canals d'una obra de Petrarca i, en segon lloc, un recull de receptes mèdiques destinades a les aus de caça. Aquest article consta de tres parts. Primerament, presentem una succinta introducció per a conéixer les característiques d'elaboració i el contingut del manuscrit. A continuació, fem una aprofundida anàlisi lèxica de la terminologia tècnica referida a la falconeria que té dues parts: una proposta de classificació del lèxic específic en els diferents camps semàntics i un glossari dels vocables més destacats. Finalment, oferim l'edició crítica d'aquest tractat de falconeria.
\end{abstract}

Paraules clau: falconeria, edat mitjana, lèxic, edició, català

Abstrat: This is a edition of an anonymous treatise on falconry, written in Catalan, and which can be, most probably, dated back to the $15^{\text {th }}$ century. Manuscript 102, kept in the Library of the University of Barcelona, contains two texts: the first is Antoni Canals' translation of a text by Petrarch, and the second a text which contains a set of medical prescriptions for game birds. This article consists of three parts: firstly, a short introduction on the writing and contents of the manuscript; secondly, an in-depth lexical analysis of the technical terminology on falconry divided into two parts: a proposal for the classification of the specific lexicon in the different semantic fields, and a glossary of the more relevant terms; and finally, a critical edition of this treatise on falconry.

Keywords: falconry, middle ages, lexical, edition, catalan

DATA PRESENTACIÓ: 14/04/2021 ACCEPTACIÓ: 30/04/2021 ·PUBLICACIÓ: 01/06/2021

1 Aquest treball s'inscriu en el marc del Projecte d'investigació subvencionat per la Generalitat Valenciana «La falconeria a la Corona d'Aragó durant la baixa edat mitjana: edició crítica de textos i estudi de documentació arxivística» (AICO/2019/255). 


\section{Antoni Mas i Miralles. Tractat de medicina per tots els ocells de caça.}

Introducció, anàlisi lèxica i edició

\section{Introducció}

La falconeria era una de les activitats que omplia el temps d'oci i de formació dels estrats socials més alts, i també, en algunes ocasions, servia perquè les classes populars pogueren afegir uns recursos monetaris i alimentaris més a la seua precària situació econòmica (Ferragud / Olmos 2021). En aquest sentit cal advertir que aquesta modalitat de caça requeria invertir importants sumes de diners, tant per a la compra d'exemplars com també per al manteniment de la salut d'aquests animals, inversió que només la reialesa i la noblesa estaven en condicions de realitzar. També hem d'assenyalar que aquest món de la venatòria implicava el treball i la participació de diferents personatges: caçadors, falconers, afaitadors, subministradors d'aliments, etc. Els falconers, que eren els encarregats de vigilar pel benestar d'aquestes valuoses aus, havien d'adquirir una sèrie de coneixements en àmbits com l'anatomia, la medicina, la farmacologia, la botànica, etc., i, a més, havien de ser prou destres i experts en l'ús de determinats utensilis, eines que eren necessàries per a la criança i l'ensinistrament dels ocells. En aquest sentit, cal tenir present que fou en l'alta edat mitjana quan els pobles àrabs portaren tots aquests coneixements a l'occident europeu, sabers mèdics i cinegètics recollits en diviersos textos, la majoria dels quals foren redactats en llatí o en àrab. Com que aquests tractats tenien l'objectiu de la formació i l'especialització dels falconers, durant l'època medieval es traduiren i es copiaren a les llengües que sorgiren arreu del continent un considerable nombre d'obres que recopilaven tota la informació relacionada amb la falconeria, de la mateixa manera que es van traduir i copiar un nombre important de treballs de caràcter tècnic $i$ científic. $^{2}$

Per descomptat que en aquest context la cultura i la llengua catalanes no van ser alienes a tot aquest corrent social, $i$ en són prova els diferents tractats medievals de falconeria redactats en català que s'han conservat. ${ }^{3}$ El text que editem en quest treball és un dels que encara restaven inèdits i que, juntament amb el Llibre dels ocells de caça-que apareix també editat en aquest monogràfic (Garcia 2021) - permet tenir a l'abast l'edició dels tractats de falconeria catalans més importants. A més a més, pot ser una bona mostra de tot aquest context lingüístic i cultural que desenvolupà el món de la falconeria, i que tingué al llarg de l'edat mitjana l'època d'esplendor.

El manuscrit $102^{4}$ que es conserva a la Biblioteca Universitària de Barcelona conté dos textos. El primer recull la traducció catalana de l'obra d'Escipió e Annibal de F. Petrarca, conegut també com Lo parlament e la batayla que agueren Aníbal e Scipió, trasllat que va portar a terme el dominic valencià fra Antoni Canals, i que ocupa els primers 24 folis $(1-24 \mathrm{v})$. El segon és un text de falconeria, anònim, possiblement del segle XV, que anomenem Tractat de medicina per a tots els ocells de caça, obra que s'estén en els altres 16 folis del manuscrit $(25 \mathrm{v}-41 \mathrm{v})$.

2 Vegeu Cifuentes (1997).

3 Vegeu una recopilació de les obres de falconeria medievals en català en Garcia et al. (2013: 58-59) i en la tesi de doctorat de Querol (2018).

4 La signatura antiga era 21-4-29. Per a una major descripció del manuscrit vegeu Miquel (1958).

SCRIPTA, Revista internacional de literatura i cultura medieval i moderna, núm. 17 / juny 2021 / pp. 335 - 374 ISSN: 2340-4841 ·doi:10.7203/SCRIPTA.17.20916 


\section{Antoni Mas i Miralles. Tractat de medicina per tots els ocells de caça.} Introducció, anàlisi lèxica i edició

Pel que fa al contingut, el text comença amb dues dedicatòries. Sobre la primera, en podem dir ben poc. ${ }^{5}$ Quant a la segona, sembla que està dedicada a una persona de la reialesa castellana, probablement es tracta de la princesa de la casa dels Trastàmara, Joana d'Aragó, segons Querol (2018: 85), dedicatòria redactada en castellà encara que ortogràficament molt catalanitzat, i que va acompanyada d'una composició poètica, incorporació que podem considerar com a singular en aquest tipus de textos. ${ }^{6}$ El Tractat comença amb la redacció en llatí d'una recepta per a curar les nafres dels ocells ${ }^{7}$, tot seguit, un conjunt de receptes, ara ja redactades en català.

Com la majoria de tractats de falconeria, l'objectiu principal d'aquests textos era descriure un conjunt de malalties i oferir-ne una serie de prescripcions mèdiques a partir de diferents tractaments pal liatius. Cada apartat està encapçalat per un epígraf on es fa referència a la malaltia (vorm, pantaix, gota, aigua al cap, càncer, porrets, etc.) o tipus d'accident (cascadura, quebrantament, etc.) o recomanacions relacionades amb la medicina preventiva (mudar, porgar, gitar ploma, ventositats, dolor d'esquena, ovament, etc.). En algunes ocasions, els apartats apareixen desdoblats, de tal manera que en el primer es descriu la malaltia i en el segon es proposen les possibles solucions farmacològiques (De menjança, La cura és aytal, etc.). Altres apartats es dediquen a oferir una sèrie d'indicacions als falconers per a saber com tractar i tenir cura dels ocells (donar viandes, sagnar, etc.). Una característica d'aquest Tractat és que a mitjan obra trobem dos apartats dedicats als cans, ${ }^{8}$ animals que també formaven part d'aquesta activitat venatòria.

Però si mirem el document en conjunt, hem de ressaltar que la distribució dels diferents apartats o capítols és clarament caòtica, ja que no se segueix cap criteri. A favor d'aquesta hipòtesi està el fet que, en opinió de Querol (2018: 87), en la còpia del Tractat intervenen sis mans. Per això Querol apunta:

després de començar la secció amb una recepta llatina per a les ferides, continua amb una exposició asistemàtica en què només s'associen uns pocs capítols per similitud de contingut mentre altres referits a la mateixa localització anatòmica, afinitat de contingut o patologia tractada es reparteixen incomprensiblement al llarg del tractat, i fins i tot s'hi encabeixen dues receptes de medicina canina (2018: 98).

\footnotetext{
5 La dedicatòria diu Al molt amat e de mi car frara. Després, una altra lletra escriu molt alt. No descartem que aquestes lletres ja estaven en el foli quan un altre copista començà la redacció del Tractat, així ho creu també Querol (2018: 88).

6 En opinió de Querol (2018: 88) «Algú pertanyent a l'elit catalanoaragonesa, probablement proper als cercles dels descendents de Ferran d’Antequera, (...) redactà la rúbrica dedicatòria i, potser, afegí el poema de lloança en castellà catalanitzat obra de Pere Torroella».

7 Segons Querol (2018: 87) el motiu de l'inici del contingut teòric en llatí pot raure en un intent de prestigiar l'obra i facilitar-ne l'acceptació, en especial en el període (proto)humanístic.

8 Sobre l'aparició de dos receptes dedicades als gossos, més concretament sobre la ronya i la ràbia, Ferragud / Olmos (2018: 122) comenten que aquesta inclusió en tractats de falconeria era ben estranya en la literatura tècnica medieval.
} 


\title{
Antoni Mas i Miralles. Tractat de medicina per tots els ocells de caça. Introducció, anàlisi lèxica i edició
}

De la informació que ofereix el text no podem deduir ni l'autor ni tampoc el lloc on va ser redactat. En opinió de Querol, aquesta còpia sembla ser una traducció al català d'un text àrab, per la procedència de moltes receptes i també per l'aparició de determinats arabismes lèxics:

\begin{abstract}
Algunes omissions podrien correspondre a la simplificació o al resum, a salts voluntaris per incomprensió o als interessos del traductor o de qui l'encomanà; desconeixem, però, el contingut de la font directa del Tractat de medicina per a tots els ocells de caça i les seves alteracions respecte al Gitriff i als Moamins. Tampoc es coneix una versió llatina de referència directa per al tractat conservat, ni a nivell documental ni de referències creuades a altres textos, motiu pel qual prioritzo la traducció directa arabocatalana (2018: 87).
\end{abstract}

A partir de la dedicatòria a la dama castellana ja esmentada, Querol (2018: 95) dedueix que el manuscrit està redactat entre 1466 i 1476. ${ }^{9}$ Raons paleogràfiques i també lingüístiques ens confirmen que es tracta, en efecte, d'una còpia d'aquesta centúria. Però amb altres arguments de caire lingüístic també ens arrisquem a proposar que hi ha indicis per a pensar que el text recull receptes d'altres textos anteriors redactats en català. Basem aquesta hipòtesi en el fet que en aquest Tractat trobem barrejades variants lingüístiques d'estrats diacrònics diferents. Exposem a continuació els casos següents:

- El mot leyt (<LACTE) conserva encara el díftong, mentre que en altres ocasions trobem la forma let.

- Hi enregistrem l'adverbi sovén que manté l'evolució de la i llatina, al costat de sovín, que és la forma predominant.

- La forma aucell apareix al costat d'ocel, hocell, etc. on s'ha produit ja la monoftongació.

- El fonema palatal nasal apareix en aquest document amb la grafia ny (almenys, any, banyada, etc.), però també amb les formes antigues ni (beniats) i amb la grafia y (beyat, beyats, etc.)

- La palatalització de la consonant lateral apareix en uns casos representada en la grafia com a $l$ (aucel, aquel, novel, etc. ), en altres casos com a il (fenoil, aneril, etc.), també com a $y l$ (serveyl, trebaylar, etc.), o yll (oceyll, buyll, paylla, etc.) i amb les consonants $l l$ (ocell, ventrell, reyells, etc.).

- El mot malaut (<MALEHABITU) manté la vocal abans de convertir-la en consonant líquida, com així la trobem en les altres formes malaltie, malalt, etc.

- La consonant - $n$ final encara es manté en mots com man i ben, al costat de les formes mà i bé.

- El text encara conté formes de la tercera persona del singular del present sense desinència (meyng, mastech, etc.).

- Sí bé hi anotem les formes de futur sintètiques (gitarà, mengerà, lexerà, etc.) també el text aporta exemples de les formes analítiques (porgar-s'à, axir-li-à, gitar-n'à, etc.).

- Pel que fa al lèxic podem afegir les variants vulls i bulls, femna i femte, sagnia i sannia, narius, neranills, nerills, nars i anerils. A més de les formes antigues alent 'alè', fener 'fondre', batalafuga 'matalafuga', jàser 'jaure', senlar 'sagnar', trer 'treure', vuyl 'ull', etc.

9 La deducció d'aquest interval està un poc forçada, ja que primer hem d'acceptar que la dama a què es refereix és la princesa Joana d'Aragó i el segon condicionant es basa en la l'edat en què suposa que es va interessar per la falconeria (després de complir 10 anys, és a dir, al voltant de 1466) i abans del seu matrimoni el 1476. 


\section{Antoni Mas i Miralles. Tractat de medicina per tots els ocells de caça.}

Introducció, anàlisi lèxica i edició

Tot i que pot semblar que són pocs els exemples, i sense descartar tampoc la possibilitat de la covariació en el text de diferents variants, aquesta variació present en l'obra ens fa pensar que, efectivament, el copista o copistes tenen a l'abast diferents textos d'èpoques diferents i, per tant, el resultat és una obra que reflecteix diversos estrats cronològics.

\section{Anàlisi lèxica}

\subsection{Classificació}

La importància social de tot allò que representava la falconeria es va traduir en l'època medieval en la creació de tractats especialitzats, la majoria dels quals eren, com ja hem comentat, uns compendis d'ornitologia que contenien un copiós vocabulari referit a camps semàntics diversos. Per això, des d'un punt de vista lingüístic, la part més ressenyable d'aquests tractats és, segurament, l'ànàlisi del corpus lèxic. En aquest primer apartat fem una classificació dels diferents camps semàntics que registrem en el Tractat.

Destaquem, en primer lloc, les referències als animals on, òbviament, hem de començar amb els ocells rapinyaires com els falcons, el sor, l'astor i l'esparver. Anotem en el text una nòmina d'animals que formen part de la dieta, com la carn que procedeix de bous, cabre, colom, crestó, galine, galine negre, horonelles, bupega, moltó (del qual s'aprofitava el cor, la fel, les gargamelles, les glànoles del col, les cuxes, el leu i la melce), mosteles, ovelles (i sobretot la melce de les ovelles), pola, polls, porcell, porch, rata, retons, tortres, vadel i vaques. Així mateix, altres animals són utilitzats com a ingredients per a alguna fórmula medicinal, així tenim les granotes, la luert, la serp, etc., o apareixen com una causa de la malaltia, és el cas dels poyls i els verms. I relacionat amb aquest camp de la falconeria, hi tenim esmentat el ca.

Els tractats medievals de falconeria dedicaven una part important a descriure l'anatomia dels falcons. La majoria dels tractats diferenciaven entre membre oficial i membre similar (Olmos 2015: 77), tot i que nosaltres farem la distinció de membres de dins i membres de fora. Pel que fa als de fora tenim en la part superior del cors, la bocha, el bech, el cap, el col, l'uyll. En aquest punt cal ressaltar el nombre de variants per a denominar el nas: narius, neranills, nerills, nars i anerils. En la part del cos tenim l'eschena i el pit, i en les extremitats tenim: les ales, les cames, la coa, les cuxes, les mans i les ungles i l'úngula. Referit al camp de les plomes, tenim les rayels de las plomes, a més de diferenciar les plomes de la coa, les coltells i les vans. I, pel que fa als membres de dins, apuntem els següents: la bocha del ventrell, els budells, el cor, la fel, el fetja, la gargamella, les glànules, les guntures de les mans, la melce, els ossos, el peladar, el pulmó o leu, el saguí, el serveyl i les venes.

En les fórmules medicinals que han de preparar els falconers trobem compostos molt diversos per a elaborar els diferents tipus de pastes, resines i engüents. Tenim condiments com el sucre blanc i el sucre candi, també la sal i la sal negre, a més de cereals com el forment i el penís, i d'espècies com el girofle, el sefrà, el pebre i el pebre llonch. Cal afegir com a productes alimentaris el blanch d'ou, la carnselada grassa, els lerdons, la mantega, la mel, el pa, el segí de porch i els vermells d'ou. Pel que fa als líquids, apuntem 


\section{Antoni Mas i Miralles. Tractat de medicina per tots els ocells de caça.}

Introducció, anàlisi lèxica i edició

els diferents tipus d'oli: oli d'emelles amargues, oli sembassi, oli de nous, holi de remus, oli trucelli, oli muselli i oli violat, o classes de vi, com el vin blanch, el vi fort i el vi de melgranes, a més del vinagre. I entre els diferents tipus d'aigua trobem: l'aygua d'endivia, l'aygua de serment, l'aygua-ros i l'ayguanafe, a més dels diversos tipus de leyt com la leyt de vaques o la de ovelles, la let de la fembre, la leyt de somera $\mathrm{i}$ la let de cabres, a més de la sanch. No falten tampoc altres productes que també eren necessaris per a la preparació d'ungüents com la cera, l'escorxe, la paylla de forment i la cendra de sarments. Cal assenyalar en últim lloc, la utilització de diferents tipus de femta: la femta d'ome, femne de porch, femte de luert, femna de las ovelles, així com també l'horine i la urine de infant.

Una part fonamental dels textos de falconeria és la recol leció d'una vasta informació sobre les malalties. En aquest text descobrim una llarga nònima de termes com fleuma, que es pot presentar en diferents parts del cos, i els bumors viscoses. Segons l'època de l'any tenim malaltia de frador o maleutie de calor. Cal destacar les malalties infeccioses i més temibles com ara: baraam, capverm, malenança, sterami, vermis o vormis (que poden aparéixer en qualsevol part del cos) i també el vòlfago. També eren malalties molt perilloses l'aygua del cap, més coneguda com l'aigua congelada, el càncer o els porrets. Com a malalties relacionades amb la inflamació tenim l'artèthica, que era la gota en les articulacions, la glànola, l'ofegament, etc., o malalties de la pell com la ronya. En altres ocasions es fa referència als símptomes, com els diferents tipus de dolor: dolor d'eschena, dolor de fetge, dolor qui ve per venchositat. En altres casos s'analitza las símptomatologia que pot presentar l'ocell, com pantaix, plagues, fístules, infladures, mal de cuxes, matèrie, etc., o d'altres com de febre, de sagnar, etc. Els accidents eren els responsables de situacions com la cascadura, el crabantament, el colp d'uyll, etc. Alguns capítols es dediquen a donar recomanacions i fer medicina preventiva com gitar la gorgua, de bexar l'oceyll, de magresa, de com porgar el cap o el ventre, o com tractar-lo quan es troba en muda, etc. Sembla que l'edat i la vellesa de l'ocell podia influir en símptomes com infladura, durícia, estar enfustegat, pelament, l'bovament, etc. Uns altres apartats adverteixen de les cures de les plomes: arrencament, menyament, vèrmens en les plomes, etc. Per últim anotem els dos apartats dedicats a l'atenció del gos referits a la ronya i a la räbie.

El camp lèxic de la botànica és rellevant en aquest tipus de document. Cal tenir en compte que la medecina medieval aprofitava les propietats naturals de les plantes, per això era imprescindible tenirne un bon coneixement per a utilitzar-les en la preparació de les cures pal liatives. En el text anotem plantes com ara alcaravia, àloe, api, ansens, armuriach, batafalua, cobaràs, coloquianda, erba lumbriguera, erba vert, estafiagre, fenoil, gingebre, hortigues, jusquiam, leborus álbum, màstech, mata, mirtre, moritort, murta, pebre lonch, pedro macedon, peònie, rachaba, riubàrber, ruda vert, salònie, sencòniga. sinigrech i sisagre. Per a la preparació d'altres receptes era necessari disposar de fruits com canela, carabacins, castaya, cols, cols verts, comí, malgrane, mostalla, nap, nous, pansas, porros, quarabaça, rave. També hi trobem fórmules que requerien la inclusió de determinades parts de les plantes, així tenim escorxe de malgrane, laor del moritort, pólvere de reyells de cols, raels de carabacins, rayells de porros, reel de nemoran, reyel del fenoil, etc. Per acabar el camp semàntic de la botànica, esmentem el nom alisiom, un arbust, i d'un arbre, el sàlzer.

Totes aquestes malalties exigien que el curador controlara i donimara un bon nombre de recursos farmacològics. Per això, a més d'un ample inventari de botànica, el text inclou una sèrie de preparats mèdics com alfení, arrop, ayguanafe, aygüe-ros, aygua de serment, be masué, momie, etc. o preparats alquímics 


\section{Antoni Mas i Miralles. Tractat de medicina per tots els ocells de caça.}

Introducció, anàlisi lèxica i edició

com blanquet, bòrach, cànfer, orpiment i orpiment vermell, salmoniach blanch, triaqua i vermayó. També són necessàries les resines $\mathrm{i}$ les gomes que s'obtenien de les plantes com alquitrà, apopònach, argentviu, bedeli, diegargant, diemargariton, elcana, galbanum, gome aräbique, sanch de dragó goma i la tramentine. A més, unes altres fórmules requerien preparats relacionats amb l'argila com arap, boli armenyci i cleda, o amb la pedra com la pedre marxe o el vidre. Per a la composició o administració d'aquests remeis terapèutics calia tenir una sèrie d'objectes com alambí, caneta, cotó, crastiri, empastre, fust, posterma, etc. $\mathrm{Cal}$ anotar que per a mesurar aquests elements amb certa precisió, els falconers comptaven amb aquests referents: avellana, castaya, ciuró, closca d'ou, diner, gra, hou, lentilla, millarès i nous.

Com ja hem esmenatat, l'objectiu primordial d'aquest tipus de tractats era mantenir la salut d'aquests animals. En aquest sentit els seus curadors havien d'apendre a preparar una dieta determinada $i$ també diferents remeis terapèutics que incloïen accions com adobar, benyar, bullir, fondre, mesclar, molre, mular, pastar, porgar, picar, remular, untar, etc. Cal afegir, finalment, la inclusió en l'obra de vocabulari específic referit al camp de la falconeria com alenar, alourar, caschavells, esmirlar, esplugar, gitar, gorga, gratar, plomada, plomar, rodador, etc.

\subsection{Glossari}

Com a complement d'aquesta classificació, exposem un glossari dels termes lèxics més destacats. Per a la definició d'aquests mots hem utilitzat diferents obres i diccionaris. Quan no assenyalem la font, és que la definició prové del Diccionari Català-Valencià-Balear(DCVB), descripcions que són les majoritàries. En canvi, quan aquest Diccionari no registra el mot o l'accepció, hem recorregut a la definició que dona J. Querol (JQ) o R. Olmos (RO) o també el Vocabulari de Faraudo (VF). En alguns mots hem considerat convenient afegir alguns comentaris que trobem en el Diccionari Etimologic $i$ Complementari de la Llengua Catalana (DECat).

Posem per ordre alfabètic el mot d'entrada en negreta i en minúscula, després oferim entre claudàtors el mot en la forma estàndard actual; a continuació, si s'escau, escrivim entre parèntesis les variants lèxiques del mot que registrem en el text. Tot $i$ això posem en infinitiu les formes verbals $i$ en masculí singular els substantius i els adjectius. En alguns casos afegim entre parèntesi el fragment on es troba el mot a fi de comprovar que la definició o l'accepció que recollim és la que correspon.

afemar, [afamar] 'Fer patir fam', (Quant l'aucell gite ģo que ha menyat, deu-lo hom afemar).

afogar, 'Matar impedint la respiració'.

alcaravia, Nom d'una umbel lífera anàloga al comí segons el DECat, en canvi per al VF és anàloga a l'anís. RO la identifica amb la Carum carvi L. (2015: 760).

alent, 'Alè'. Variant antiga i rara d'alè segons el DECat.

alfení, 'Pasta de sucre pastada amb oli d'ametles dolces'. 


\section{Antoni Mas i Miralles. Tractat de medicina per tots els ocells de caça.}

Introducció, anàlisi lèxica i edició

alisiom, 'Arbust de la família de les solanàcies'. JQ $(2018: 150)^{10}$ creu que aquest mot procedeix de la forma lici.

àloe, 'Planta liliàcia de diverses espècies del gènere Aloe, de les quals s'obté el sèver'.

alourar, [llourar] (alaurets) En el context de la frase sembla referir-se a cridar el falcó per mitjà del lloure, (quant volrets l'aucel alourar o clamar a la mà).

alquitrà, 'Substància resinosa de color negrenc o vermell fosc, que s'obté per destil lació seca de diverses matèries orgàniques i principalment de la llenya de faig'.

aluda, 'Pell d'ovella o de be, adobada i suavitzada, i que en blanc o colorida s'emprava per fer guants, bosses, folradures de llibre, etc.'.

alum, 'Sulfat doble d'un metall trivalent i un altre monovalent capaços de cristal litzar en octaedres regulars amb dotze mol lècules d'aigua de cristal lització'. Segons el VF 'Sal mineral (sulfat doble d'alirmina: de potassa) que serveix a clarificar l'aigua i a fixar les tintures sobre les teles'.

amorós, 'Amable, que tracta els altres amb suavitat i dolcesa', (fe'l plomar e tirar sovén, car pus amorós ne serâ).

anelar, [anhelar] 'Desitjar amb vehemència', (e no s fer dels pits, s'anela e és-ne pus prinats).

aneril, 'Nas'.

anet, 'Planta de la família de les umbel líferes'. Segons el VF la planta és semblant al fenoll.

apopònach, 'Gomo-resina que s'extreu d'una planta oriental del gènere Balsamodendron'.

arap, Segons JQ (2018:150) és una forma corrompuda del borach armeni. (Veg. boli armenyci).

ardidament, 'Amb ardiment, sense temor'.

ardrial, Sembla ser un derivat d'ardit, (e aurà àvol alé e no's vol tost ardrial).

argentviu, 'Metall blanc i lluent com l’argent, més feixuc que el plom, i líquid a la temperatura ordinària'.

armuriach, Possiblement es referisca al rave 'Cochlearia armorica' segons JQ (2018: III-399).

arrop, 'Most de raïm, espessit per ebullició i evaporació'.

artèticha, [artètica] 'Qui pateix de gota a les articulacions', (Quant l'aucel ha inflades les cames ho les mans per artèticha).

astor, (estor, stor) 'Ocell carnisser de la família de les aquílides'.

10 Si no indiquem que la pàgina correspon al vol. III, és que és del primer volum. 


\section{Antoni Mas i Miralles. Tractat de medicina per tots els ocells de caça.}

Introducció, anàlisi lèxica i edició

aumagrar, [emmagrir] 'Tornar magre', (si açò no li val e aumagresque, dats-li a menjar let de vaques).

àvol, 'Dolent, mal'.

àyer, 'Aire'.

aygua de cap, Segons JQ (2018: 160) estadi inicial de l'aigua congelada, 'malaltia dels falcons i altres aus carnisseres'.

ayguada, [aiguada] 'Acte de rentar amb aigua', (finalment pesats-la per $V$ ayguades)

ayguanafe, [aiguanafe] 'Aigua de flor de taronja, que s'empra com antiespasmòdic'.

aygua-ros, [aigua-ros] 'Aigua de roses destil lades'.

baraam, JQ comenta que el mot es refereix a una altra malaltia, l'afecció respiratòria de l'ocell de caça que cursa amb expulsió de mucositat per les narines, ronquera i disnea o intolerància a l'exercici. No apareix al DCVB ni al DECat.

batafalua, [matafaluga] 'Planta de la família de les umbel líferes: Pimpinella anisum L.'.

be mesué, Preparat amb diverses pólvores segons JQ (2018: 330). Segons RO (2015: 824) algunes píndoles rebien el nom propi del famós metge àrab Mesué i que servien per al tractament dels traumatismes, com ara la píndola d'hermodàctils de Mesué i la píndola d'euforbi de Mesué, (Per ocel cascat auràs pólvora de be mesuè).

bedeli, Segons JQ (2018: 330) es tracta de la goma delli. Per a RO (2015: 772) és la «gomorresina obtenida de algunos árboles orientales pertenecientes al género Commiphora».

bexar, [baixar] (bexat, bexar, bexerets) Possiblement vulga dir 'fer perdre pes'. El DCVB no documenta aquesta accepció. En opinió de JQ (2018: III-17) cal interpretar 'Inclinar endavant, disminuir-ne l'alçada. En el cas del cap de l'ocell, com a signe de debilitat o malaltia', (per a abaxar bé lo falcó o lo ocell no li donets de aquestes viandes).

blanquet, 'Carbonat de plom, que es presenta en forma de pólvora blanca'.

boli armenyci, Forma corrompuda de bolarmeni, 'Espècie d'argila ferruginosa vermellosa'.

bòrach, [bòrax] 'Tetraborat de sodi', (A tal malaltie fets-hi aytal cura: prenets holi e vinagre e fil e bòrach).

caneta, 'canyeta', (prin una caneta e rau-li bé la bocha).

cànfer, [cànfera] Possiblement es refereix a l'alcanfor, càmfora, 'Substància sòlida, blanca, d'olor forta i aromàtica, de gust amargant i ardent, que s'obté de l'arbre Laurus camphora i s'usa molt en medicina'.

capvorm, (capverm) En opinió de JQ (2018: 61) és una altra afecció indeterminada de l'ocell de caça, probablement limitada al cap. (Veg. vorm). 


\section{Antoni Mas i Miralles. Tractat de medicina per tots els ocells de caça.}

Introducció, anàlisi lèxica i edició

cascadura (caschadura) 'Contusió amb trituració de teixits'.

castor, Segons VF 'Matèria antiespasmòdica extreta del castor', (dats-li a menyar un poch de éloe e de castor).

centidure, [sentidura] 'Afecció indeterminada de l'ocell de caça. Probablement dolor, potser a la palpació'.

cleda, [greda] 'Argila blanquinosa que s'empra principalment per a treure taques i desengreixar draps'.

cobaràs, [fabaraç] (cabarràs, cobarràs) 'Planta renunculàcia de l'espècie Delphinium staphisagria'.

coloquianda, [coloquinta] 'Planta cucurbitàcia de l'espècie Citrullus Colocynthis'. Per a VF és una 'Espècie de cogombre molt amarg'.

coltell, 'Cadascuna de les plomes més amples de l'ala d'una au'.

continent, 'Aire i actitud del cos; i per ext., disposició de la voluntat cap a una manera determinada d'obrar', (e que li sàpie seguir le mà als continens que son aucel ferà).

corp, [corb] 'Que té el cos deformat i desviat de la línia recta', (e tindrà son cap corp).

crabantament, [quebrantament] 'Acte de crebantar; irrupció violenta amb fractura'.

crastiri, [clisteri] 'Lavativa'.

crebentar, [quebrantar] 'Fer perdre consistència o resistència un cop violent a una cosa'.

crestó, 'Boc castrat'. Segons VF ‘Bou, moltó o boc castrat'.

crivell, 'Espècie de garbell fet de pell amb foradins'.

cural, 'Piloteta de plomes fluixes, de roba usada o de cotó, abeurada de substàncies medicinals, que els caçadors i falconers donaven als falcons per purgar-los'

curis, [turis] Segurament és corrupció per la forma turis en opinió de JQ (2018: III-349), 'Ensens'. cuytar, [cuitar] 'Fer anar de pressa'.

desexir, Pel context sembla referir-se a 'eixir', 'anar-se'n volant de la mà del falconer', (e no's vol tost ardrial desexir de la mà).

desfici, 'Agitació produïda per un mal físic o moral, per una passió, un desig, etc.'. Segons el VF 'Neguit, malestar, displicència'.

diamargariton, Segons JQ (2018: III-348) 'compost que incloïa perles, d'indicació cardíaca' (2018: 163) El Vocabulario de Comercio Medieval amplia la difinició 'confección cuya composición tiene 


\section{Antoni Mas i Miralles. Tractat de medicina per tots els ocells de caça. Introducció, anàlisi lèxica i edició}

por base perlas trituradas batidas en miel colada junto a cilantro, coral, aljófar, goma arábiga, rasuras de marfil, cuerno de ciervo y alcanfor, añadiendo después almizcle y diluyéndolo en agua de rosas'. ${ }^{11}$

diegargant, Possiblement fa referència a un tipus de goma. RO (2015:789) registra aquesta forma de la qual diu «El término se empleaba para designar varias plantas del género Astragalus, particularmente $A$. gummifer Labill. y $A$. tragacantha L., así como la goma de ellas obtenida», (prenets gome aräbiqua e diegargant e fets-ho fondre en aygua).

digest, (digeste) 'Transformat dins el cos animal en matèria pròpia per a la nutrició'.

diner 'Porció o quantitat de cosa que val un diner', (e picats los renchs lo pes de un diner ab aytant de nou cremada).

elcana, En opinió de JQ correspon a «la quina, que es una goma que semeja al sacapin» (2018: 151).

encens, (ancens) 'Resina aromàtica que en cremar-se exhala un perfum fort i agradable, i que sol usar-se en les funcions solemnes d'església com homenatge a la Divinitat'.

enfogament, [ofegament] Pot referir-se a una infecció respiratòria. No hi ha entrada en el DCVB encara que sí apareix enfogar-se 'Tapar-se el cel, ennuvolar-se', (Quant l'aucel ba enfoguament, que no pot alenar)

enfustegar, D'acord amb JQ (2018: 100) es refereix a l'ocell de caça rígid com una fusta i que rebutja volar, símptoma de l'afecció anomenada esterami.

escorxadassa, [escorxadissa] 'Que pot escorchar-se'.

escumar, (escumada) 'Treure l'escuma d'un líquid'.

esmoltir, [esmirlar] Sembla una corrupció de esmirlar 'Evacuar del ventre', (posats-lo en la perxa e astigua tant tro esmoltesqua).

esplugar-se, 'Llevar les puces o els polls'. JQ (2018: III-111) creu que és quan l'ocell es grata amb el bec, per molèstia en aquella zona.

estafiagre, [estafisàgria] (Veg. fabaraç).

estancar, 'Aturar el curs d'un líquid', (e les nerills li stanquen e crex-li l'aygua als vulls).

fabaràs, [fabaraç] (fabarràs) 'Planta renunculàcia de l'espècie Delphinium staphisagria.'

femne [femta] (fetme) 'Excrement; fem expel lit per un animal'.

fener* [fendre] 'Dividir una cosa en dues o més parts per ruptura o per tallament', (fenets-li ab vidre tayant là unt aurà imflat).

11 Vocabulario de Comercio medieval. Legado Gual Camarena. Universidad de Murcia, s.v. diamarguariton. [https://www. um.es/lexico-comercio-medieval/index.php/v/lexico/8175/diamarguaritom]. 


\section{Antoni Mas i Miralles. Tractat de medicina per tots els ocells de caça.}

Introducció, anàlisi lèxica i edició

fenoil, [fenoll] 'Planta umbel lífera de l'espècie Foeniculum officinale'.

feutre, 'Feltre', (e prenets un drap de feutre e mulats-lo an aquel vi).

fil, Desconeixem aquest component, (A tal malaltie fets-hi aytal cura: prenets holi e vinagre e fil e bòrach).

fístola, 'Canal anormal format per una úlcera o cavitat estreta en la pell o en les membranes mucoses'.

flach, 'Magre; prim de carn'.

fleuma, [flema] 'El més fred i humit dels quatre humors del cos, segons els metges antics'.

fumar, 'Exposar a l'acció del fum; ennegrir o fer tornar fosc per l'acció del fum', (Si l'aucell és fumat, met-li hom e t nars oli violat).

fust, 'Fusta', (cramats-li-ho ab fust de mirtre).

galbanum, [gàlban] 'Goma resina groguenca semblant a l'asafètida, que s'extreu de certes plantes asiàtiques i africanes del gènere Ferula’.

galina negre, Espècie de gallina no recollida en el DCVB.

gingebre, (gingibre, gingebra) 'Planta zingiberàcia de l'espècie Zingiber officinale, originària de l'Índia i cultivada per aprofitar el seu rizoma gros i olorós, emprat com a condiment'.

girofle, 'Clavell d'espècia'.

gits, Segons JQ (2018: III-145) es tracta d'una malaltia relacionada amb patologies digestives. Segurament és una corrupció del mot àrab gis 'guix', perquè la femta de les aus tenia un aspecte paregut a l'algeps, (malaltia que hom apella gits).

glànola, 'Inflamació pestilencial dels ganglis limfàtics, principalment dels engonals, de l'aixella o del coll'.

gome arábique, 'La més blanca, pura i transparent, que és exsudada per una acàcia africana.'

gota, 'Malaltia caracteritzada per una inflamació molt dolorosa de les parts fibroses i lligamentoses de les articulacions, en les quals es formen dipòsits d'urat de sodi'.

gratar-se, 'Fregar amb les ungles'

gravillosa, Derivat de grava. Mot no documentat en el DCVB. (fets-li metre devant una somada de arene gravillosa).

herba lunbriguera, [herba llombriguera] 'Crassulàcia de l'espècie Umbilicus pendulinus'.

houament, Segons JQ (2018: III-214) «Acció d'ouar la femella d'ocell de caça. Possible afecció associada a la posta, com ara una retenció d'ou». Mot no registrat en el DCVB. 


\section{Antoni Mas i Miralles. Tractat de medicina per tots els ocells de caça.}

Introducció, anàlisi lèxica i edició

hupega, [upega] 'Puput'. Segons JQ (2018: III-299) d'aquest ocell s'extreu sang per utilitzar-la com a medicament.

jàser, 'Jaure'.

jusquiam, 'Planta solanàcia del gènere Hyoscyamus, principalment les espècies $H$. albus i $H$. niger, més coneguda amb el nom d'herba queixalera'.

laor, [lavor] 'Òvul fecundat i madur, part del fruit que desenvolupant-se en condicions adequades dóna naixença a una planta; conjunt draquestes parts del fruit'.

leborus album, Segons JQ (2018: III-349) es tracta d'una herba, i el mot és un llatinisme procedent d'El lèbor blanc, 'baladre'.

leixar, [lleixar] (lexarets, lexats) 'Deixar'.

lerdó, [lardó] 'Cadascun dels trossos de sagí més o menys rostits, que resten després d'extreure’n el llard'.

leu, 'Pulmons'.

loure, [lloure] 'Menja que es mostrava als ocells de caça per atreure'ls cap al caçador'.

luert, [lluert] 'Llangardeix'.

magresa, 'Qualitat de magre'.

malenança, 'Infecció'.

malgrane, (melgrane) 'Magrana'.

màstech, [màstec o màstic] 'Resina translúcida, groguenca, que s'extreu per incisió del llentiscle'. mata, 'Planta terebintàcia de diferents espècies del gènere Pistacia', (prenets nous veylles e such de mata) matèrie, 'Pus, humor de la supuració'.

menjança, 'Polls del cap, i picor que fan aquests o altres paràsits del cos humà', (hom menjanca, ço és, quant s'eranquen les plomes e tenen-les al bech e no les vol gitar).

milar, (millares, milaresos) Pes 'Nom de la moneda d'argent de més valor que encunyaven els emperadors d'Orient en l'edat mitjana, i que en el sistema monetari romà bizantí equivalia a la mil lèsima part d'una lliura d'or', (prenets de la peònie lo pes de un millarès).

mirtre, D'acord amb JQ (2018: III-381) segurament es refereix a la murta. 'Planta mirtàcia de l'espècie Myrtus communis', (cramats-li-ho ab fust de mirtre).

momia, 'Nom que es donava a la carn putrefacta i a la substància exudada dels cadàvers embalsamats, a les quals s'atribuïen propietats curatives'. 


\section{Antoni Mas i Miralles. Tractat de medicina per tots els ocells de caça.}

Introducció, anàlisi lèxica i edició

morritort blanc, Espècie no documentada en el DCVB, (dats-li a menjar carn ab moritort blanch).

morritort, (moritor, muritort) 'Planta crucífera de l'espècie Lepidium sativum, de fulles inferiors pinnatífides i les superiors linears, i raïm fructífer llarguet i bastant fornit, flors blanques i silícules ovalades i alades'.

mustela, 'Mamífer carnisser de la família dels mustèlids, espècie Mustela vulgaris, d'uns $25 \mathrm{~cm}$. de llargària, cos llarguer, potes curtes, pèl bru rogenc amb les parts inferiors blanques; és animal molt viu i lleuger i s'alimenta de mamífers i aus casolane'.

nar, 'Forats del nas', (que li mates per lo nars).

nemoran, Es tracta de la celidònia 'Planta de la família de les papaveràcies'.

neranill, Es refereix a nariu. Mot no documentat en el DCVB.

neril, 'Nariu'.

nisayt, En opinió de JQ (2018: III-203), mot segurament relacionat amb nienc.

oli de remus, Possiblement fa referència a l'oli de rici.

olí musellí, Tipus d’oli almescat.

oli sembassí, Tipus d'oli. Segons JQ (2018: III-384) es refereix a l'oli senibassi.

oli trucellí, Possiblement es refereix a l'oli ben pur en opinió de JQ (2018: III-385).

oli violat, Segurament es refereix a l'oli muselli segons JQ (2018: III-385).

oreig, 'Vent suau i fresc'.

orpiment, 'Trisulfur d'arsènic, de color groc de llimona, molt tòxic, usat en tintoreria, pintura i pirotècnica, i antigament en medicina'.

ouar, 'Covar, fer néixer els ous'. Segons JQ (2018: III-212) es refereix més concretament a 'desenvolupar els fol licles ovàrics la femella d'ocell de caça, procés que finalitza en la posta de l'ou', (Quant l'esperver ho altre aucell és houat).

pantax, [panteix], 'Respiració fatigosa'.

pebre lonch, [pebre llong] 'fruit d'una planta semblant a la pebrera, però de forma llargueruda i de propietats més actives que el pebre ordinari'.

pedre marxe, Desconeixem el tipus de pedra a què fa referència.

pedro macedon, Segons JQ (2018: III-395) es refereix al julivert. 


\section{Antoni Mas i Miralles. Tractat de medicina per tots els ocells de caça.}

Introducció, anàlisi lèxica i edició

pelement, [pelament] VF diu 'Acció i fet de pelar o pelar-se'. Segons JQ (2018: III-225) es tracta d'una afecció de l'ocell de caça que cursa amb caiguda de plomes del coll, cap i ales, diferent de l'arrancament i menjament $\mathrm{o}$ menjança, autotraumàtiques o agressions mecàniques del propi ocell amb el bec. Aquest mot no té entrada en el DCVB.

peònia, 'Planta ranunculàcia de diferents espècies del gènere Paeonia, i principalment la Paeonia humilis, de flors vermelles o rosades, grosses, fulles molt dividides i arrels tuberoses'.

perxar, En opinió de JQ «Potser realitzar moviments anormals i repetitius a la perxa degut al malestar o neguit, o bé esternudar; amb menor probabilitat, moure oscil latòriament la cua, indicatiu de dificultat respiratòria» (2018: III-233). El mateix autor afig «El perxar freqüent descrit a la simptomatologia és explicat pels Moamins com tremolor i bipedestació dificultosa» (2018: III-214), (conexerets-le con tindrà la care inflada e à los vulls plens d'aygua, e vol perxar e no ha què).

plaga, 'Nafra'.

plomar, 'Perdre les plomes per a mudar-les'.

porret, 'Tumor dur produït en les cames dels animals de peu rodó i dels ocells'.

posterma, [apostema] 'Depòsit o acumulació de pus o matèria dins una cavitat anormal, formada en els teixits del cos'.

rachaba, D'acord amb JQ (2018: III-398) possiblement correspon al nom d'una herba, que en castellà correspon a çabga almerich. D’aquest terme, RO diu «La versión árabe conservada contiene en una ocasión sib $\square$ g al-lakk (tinte de la laca) y en otra sabg al-lake (goma de la laca)» (2015: 774).

rench, 'Paparra inflada de xuclar sang'. Segons JQ (2018: III-260) es refereix a l'ectoparàsit Boophylus spp.

retraure, 'Tenir tendència, estar acostat (a tal o tal qualitat o manera d'esser); tenir semblança, semblar (a tal o tal cosa)'.

riubàrber, 'Rizoma de plantes poligonàcies de diverses espècies del gènere Rheu barb $\square$ rum, molt usat en l'edat mitjana com a medicament i com a aliment'.

rodador, En opinió de JQ (2018: III-262) «dit de l'ocell de caça que roda, en la seva accepció falconera. Normalment referit a rodar com a vici o defecte de l'ocell de caça».

ronya, 'Malaltia cutània contagiosa, comuna a l'home i a diferents animals (sobretot quadrúpedes), caracteritzada per la formació de petites vesícules que fan molta picor, i causada per l'insecte Sarcoptes scabiei'.

ruda, 'Planta rutàcia de l'espècie Ruta graveolens, de troncs drets i ramosos, de 60 a $80 \mathrm{~cm}$. de llargada, fulles alternes, grosses, compostes de fulletes partides en lòbuls llargueruts, blavoses; flors de quatre pètals, grogues, en corimbes terminals, i fruit capsular de moltes llavors negres i menudes; fa una olor forta i fastigosa'. 


\section{Antoni Mas i Miralles. Tractat de medicina per tots els ocells de caça.}

Introducció, anàlisi lèxica i edició

sacnat, [sagnar] (segnats) 'Treure sang a algú obrint-li una vena, generalment per a produir un efecte curatiu'.

sagnie, [sagnia] (sacnie, sannia) 'Operació de treure sang d'una persona o d'un animal obrint-li una vena'.

saguí, És el 'greix d'una animal', però en l'expressió rompre son sagui que trobem al text sembla referir-se a una malaltia, segons $\mathrm{RO}$ «Con las expresiones de quebrantamiento del saín, sain quebrado o desainamiento se refieren los tratados de cetrería a una dolencia, calificada como peligrosa, que puede acontecer a las aves cuando, después de varios meses de inactividad, son sacadas de la muda para reanudar la caza» (2015: 539), (lo feu trebeyllar per pehor de rompre son sagui).

salmoniach, (salmoniach blanch) 'Sal armoniac'. RO relaciona el terme amb armoniac «Se trata de una sustancia mineral, denominada también en los textos antiguos sal armonica o anuxatir, que se identifica con el cloruro amónico» (2015: 766).

salònia, [celidònia] En opinió de JQ (2018: III-403) hi ha una corrupció de sal<id>ònia. 'Planta de la família de les papaveràcies: Chelidonium majus L'.

sàlzer, 'Arbre de la família de les salicàcies, de l'espècie Salix alba'.

sament, [sement] 'Llavor'.

sanch de dragó, [sang de dragó] 'Suc resinós vermell i amarg que s'extreu del tronc de la planta anomenada dragó i dels fruits de certes palmeres'.

sanigrés, Mot derivat d'una corrupció de senigrec, esmentat com 'finigrech', segons JQ (2018: III407). (Veg. sinigrec).

sarcatale, [sarcocol la] 'Goma aromàtica i amargant que antigament s'usava per a curar ferides'.

secudar, [secudir] 'Separar de si una cosa, llançar-la, desprendre-se'n amb un moviment sobtat', $(e$ que no s secuda tan bé com sol).

segnar, [sagnar] 'Treure sang a algú obrint-li una vena, generalment per a produir un efecte curatiu', (li és bo segnar de las ungles).

sencòniga, [santòniga], 'Planta composta olorosa i amargant, de l'espècie Artemisia cina, de la qual s'extreu la santonina'.

senlar, (Veg. sagnar), (devets tenir l'aucell a l'àyer e senlar-lo de les ungules).

sinigrech, [fenigrec] 'Planta lleguminosa de l'espècie Trigonella foenum graecum L., que és una herba que es fa de $80 \mathrm{~cm}$. d'altària i té les flors sèssils i els llegums llargs i gairebé cilíndrics; es cria per dins el blat i té la propietat drembriagar, per la qual cosa el comprador del blat pot rescindir el contracte si hi troba excessiva quantitat de fenigrec barrejat'. 
sisagre, (Veg. fabaras).

somada, 'Càrrega d'un animal de bast, la qual és equivalent a tres quintars', (fets-li metre devant una somada de arene gravillosa).

squiu, [esquiu] 'Esquerp, refractari al tracte', (veurets qu él se pleguarà e se’n farà squiu).

sterami, [esterami] Segons JQ (2018: III-112) «es tracta d'una afecció indeterminada de l'ocell de caça, amb la qual adopta una postura antiàlgida, enfustegant-se i deixant penjar l'ala dreta, i que afecta especialment a la part dreta de l'ocell».

sucre candi, 'El sucre que amb successives clarificacions i una evaporació lenta roman reduit a cristalls transparents'.

tans, Mesura de pes que no hem pogut identificar, o possiblement dos tans vulga dir 'el doble', (prenets pes de un millars e dos tans d'orpiment). RO parla del tan com una planta no identificada (2015:836).

tèrcia, [terça] 'Tercera hora del dia, en la divisió romana del temps; corresponia a les nou del matí actuals', (una vaguada lo jorn, ço és, a mitge tèrcie).

terçol, 'Es deia especialment dels ocells de presa mascles'.

tramentine, [trementina] 'Resina semifluida exsudada pel terebint, el pi i altres coníferes'.

trer, 'Treure'.

triaqua, [triaca] 'Antídot que s'usava antigament, compost d'un gran nombre d'ingredients i aplicat principalment a guarir mossegades d'animals verinosos'.

úngula, En el context on apareix aquest mot sembla referir-se a la pràctica de tallar la punta de l'ungla perquè n'isca sang, (senlar-lo de les úngules).

vans, Són les plomes de l'ala que venen a continuació dels coltells. Segons VF es refereix a les ales de l'ocell, (tro que ha mudat tots los coltells e los vans).

ventrell, 'Estòmac'.

vermayó, [vermelló] 'Sulfur vermell de mercuri, usat en pintura'.

vermell, 'Rovell de l'ou', (pren los vermells de tres ous).

vèrmens, [verm] 'Cuc'.

vescositat, [viscositat] 'Qualitat de viscós; cosa viscosa'. JQ considera el mot com a sinònim de ventositat (2018: III-303).

vi de melgranes, [vi de magranes] 'Suc fermentat d'un fruit que no sigui raïm’. 
vòlfago, En opinió de JQ (2018: 162) es tracta de l'avolfago, «una afecció que produeix ofegament o disnea a l'ocelly. Probablement es referesca al terme huéffago, malaltia molt habitual en la falconeria castellana segons RO, i que té el mateix significat: «el buéffago o buérfago, que parece el término más propio de los halconeros castellanos para referirse a una enfermedad del pulmón de las aves» (2015:474). El text ja confirma que el terme és sinònim de pantaix (vòffago, que vol dirpentayx). No apareix al DCVB ni al DECat.

vorm, (vermis, vormis) 'Borm, malaltia dels animals de peu rodó'.

vull, [ull] (hulls, huylls) 'Ull'. 


\section{Antoni Mas i Miralles. Tractat de medicina per tots els ocells de caça.}

Introducció, anàlisi lèxica i edició

\section{Bibliografia}

Cifuentes, L. (2006) La ciència en català a l'Edat Mitjana i el Renaixement, Barcelona, Publicacions i Edicions de la Universitat de Barcelona, col. «Blaquerna» 3, (1 a ed. 2002).

Cifuentes, L. (1997) «Traslatar sciència en romans catalanesch. La difusió de la medicina en català a la baixa edat mitjana i el Renaixement", Llengua \& Literatura, 8, p. 7-42.

DCVB: Alcover, A. / Moll, F. (1930-19629) Diccionari Català-Valencià-Balear, Ciutat de Mallorca, Moll, 10 vols., http://dcvb.iec.cat/.

DECat: Coromines, J. (1980-1990) Diccionari Etimològic i Complementari de la Llengua Catalana, 9 vols., Barcelona, Curial.

Ferragud, C. / Olmos R. (2018) «La cura de cavalls, gossos i ocells de caça a la Corona d'Aragó: entre la literatura específica i la seusa assistència mèdica», Els animals a l'Edat Mitjana (coord. per Flocel Sabatí i curull i Maite Pedrol), p. 119-140.

Ferragud, C. / Olmos R. / Bataller, V. (2021) «Galiana: història d'un falcó», SCRIPTA, Revista internacional de literatura $i$ cultura medieval i moderna, núm. 17 p. 413-481.

Garcia, M. (2021) «El Llibre dels ocells de caça, o Flors de les receptes medicinals per a ocells de caça», SCRIPTA, Revista internacional de literatura i cultura medieval i moderna, núm. 17 p. 280-336.

Garcia, M. / Mas, A. / Arronis, C. / Càmara, H. (2013) El Llibre de caça. Estudi i edició d'un tractat de falconeria medieval, Alacant-Barcelona, Institut Interuniversitari de Filologia Valenciana, i Publicacions de l'Abadia de Montserrat.

Miquel, F. (1958) Inventario General de Manuscritos de la Biblioteca Universitaria de Barcelona, I. Madrid: Direcciones Generales de Enseñanza Universitaria y de Archivos y Bibliotecas, Servicio de Publicaciones de la Junta Técnica, 1958-1969. - 4 v., p. 71-77.

Olmos, R. (2015) Los cuidados de las aves de caza Estudio de la medicina de las aves a partir de los tratados castellanos de cetrería (siglos XIII - XVI), tesi de doctorat, Universitat de València [https://roderic. uv.es/handle/10550/50872].

Querol, J. (2018) L'art de la falconeria a la Corona d'Aragó durant la baixa edat mitjana: edició i estudi dels tractats escrits en català, tesi dedoctorat de la Universitat Autònoma de Barcelona. [https://ddd. uab.cat/pub/tesis/2019/hdl_10803_666811/jqsa3de3.pdf].

Sciència.cat, coord. per Lluís Cifuentes i Antònia Carré, Universitat de Barcelona, 2006- < $\underline{\text { http:// }}$ www.sciencia.cat>.

VF: Vocabulari de la llengua catalana medieval de Lluís Faraudo de Saint-Germain [https://www.iec.cat/faraudo/]. 


\section{Antoni Mas i Miralles. Tractat de medicina per tots els ocells de caça.}

Introducció, anàlisi lèxica i edició

\section{Edició del Tractat de medicina per tots els ocells de caça.}

\subsection{Normes d'edició}

a) Seguim com a norma general els criteris d'edició de la col lecció «Els Nostres Clàssics» de l'editorial Barcino.

b) Regularitzem l'ús de les grafies $u / v, i / j, c / g$. Reproduïm com a $c$ totes les $c ̧$ amb valor alveolar, i com a $c ̧$ totes les $c$ que apareixen davant de les vocals $a, u \mathrm{i} o$, en la majoria de casos per falta del traç corresponent.

c) No marquem el desenvolupament de les abreviatures

d) Hem reduït sempre les grafies dobles, tant les etimològiques com les no etimològiques si responen només a un únic fonema:

e) Regularitzem la grafia de la nasal palatal nny, yn o nyn >ny.

f) L'accentuació adoptada correspon al timbre vocàlic propi de la variant oriental, zona d'on segurament prové el manuscrit. Usem l'accent diacrític en els casos que indica la normativa actual i, excepcionalment, en altres mots que poden prestar-se a confusió com: àls (altre), là, llà (allà), sí (aixì), à, é i ém (haver), té (tenir), péra/péres (pedralpedres), mès (participi de metre), etc.

g) Seguim els criteris actuals pel que fa a puntuació, separació de paraules, majúscules i minúscules, apòstrof, guionet, accent i dièresi.

h) Emprem la dièresi damunt la $y$ en mots com aïna, constitujides. En prescindim en els casos de paraules amb $h$ antihiàtica com tribumfo, jabia, tradubit, etc., també les formes verbals de l'imperfet d'indicatiu com dë̈a, fë̈a, hö̈a etc, ja que es tracta d'un text anterior al segle XV.

i) Representem amb un punt volat la pèrdua d'una vocal en una aglutinació quan no s'hi pot utilitzar l'apòstrof: que $:$, vostr apetit, etc.

j) Pel que fa a la numeració de les pàgines, apareix entre claudàtors la xifra de la pàgina acompanyada de r (recto) o v (verso).

k) Transcrivim com a un/una, dos/dues, tres/terça les xifres romanes I, Ia, II, IIa, III, IIIa. Els numerals romans els editem en versals i sense punts ni davant ni darrere.

1) Recollim en les notes a peu de pàgina les particularitats següents que presenta el manuscrit:

- Indiquem els casos de mots que cal ometre (e de] de), mots ratllats (per] te per) i mots interlineats (mare $\{$ sua\}] mare sua). També corregim errors (reastràs] restaràs).

- Incloem també en les notes algunes recomanacions per a determinades lectures (belles > Llegiu balles). 


\section{Antoni Mas i Miralles. Tractat de medicina per tots els ocells de caça. Introducció, anàlisi lèxica i edició}

\subsection{Edició $^{12}$}

\section{[Tractat de medicina per tots els ocells de caça]}

$[25 \mathrm{v}]^{13}$

Muy alta e muy poderosa prinsesa, mi senyora, ahunque ${ }^{14}$ por vuesa altesa m'a sido mandado mutxas veses ysiese hun tratado de melesina para todas aves de casa, asta qui $^{15} \mathrm{mi}$ insufisiente ingenio no a sido para ponerse en cosa tan peligrosa.

Entre las hotras, soys vos,

ho, dueya d'esta mi vida,

del traste común salida

huna en el mundo de dos.

Vos soys la qui desfaséys

lo que mis versos contienen,

vos soys la qui mereséys

renombre y honor cobréys,

entre las hotras diversas.

[26r] Recipe: sangis drachonis, sarcatale, ${ }^{16}$ boli armenyci, curis ${ }^{17}$ masticis, opeponat, ${ }^{18}$ ana creatur, et fiat pulvis. Valet ad consolacio vulterum ${ }^{19}$ avium et contra hominum ${ }^{20}$ esser. $^{21}$ Debentur sire ${ }^{22}$

12 Agraïm a Ricardo Olmos l'oferiment d'una primera transcripció del text i a Marinela Garcia la revisió de l'edició.

$13 \mathrm{El}$ Tractat comença amb unes línies escrites per un copista que, segurament, no és l’autor del text i que posteriorment va posar: «Al molt amat e de mi car frara, la present no és per pus, sinó com jo é donat raçapta en lo que us sabeu». En una altra línea, una mà diferent posa «al molt».

14 abunque] abunqe ms.

15 asta qui] ata quí ms.

16 sarcatale] sarcocole J. Querol (JQ).

17 curis] turis JQ.

18 opeponat opoponac JQ.

19 vulterum] vulnerum segons JQ.

20 bominum $]<$ vulnerum $>$ hominum JQ.

21 esser] etiam JQ.

22 sire] $s<c>$ ire JQ.

SCRIPTA, Revista internacional de literatura i cultura medieval i moderna, núm. 17 / juny 2021 / pp. 335 - 374 
quod quando vulaveris ${ }^{23}$ est in loco verboso, ${ }^{24}$ sic in pede, non debet vulnerus claudil ${ }^{25}$ sed debet teneri apertum, et ideo non ponitur de dicto polvore sed de ungento quod sequitur, vel poni ibi de ungento superiori et erit melius quam serpencie duas partes apostolicon, tertiam, fiat ungentum et pone super vulnerus nervosum.

\section{A vormis}

Astor qui ha vermis al cap, pren los vermells de tres ous e fe'ls cremar en une olleta de ferre, e faran un oli, ${ }^{26}$ e d'equel holi li metràs per las neranills ${ }^{27}$ e li fragaràs lo peledar.

\section{A vermis}

Altre cure. Pren del such de la reyel del fenoil e de le let de la fembre, aytant de l'un com de l'altre, e mescla-o tot, e met-li'n en les nerills e li'n fregua lo peledar.

\section{A vormis}

Enperò, devets seber que $\mathrm{a}^{28}$ vaguades ve esta melaltie [26v] per calor, e [a] vaguades ${ }^{29}$ per frador. $\mathrm{E}$ axí que, ${ }^{30}$ si ve per calor, devets tenir l'aucell a l'àyer e senlar-lo de les úngules, e dats-li coses de fradors. E, si de frador li ve, dats-li cosses caldes. E conexerets ${ }^{31}$ quant ve de frador ho de calor; que, si ve de calor, le metèrie o l'esmirladura que gitarà serà quax vermella o ratraurà a vermellor, si que no és matèrie freda. Mas, freda o calda, porgats-li lo ventrell ab sucra candi, que li dons ab un poch de carn benyada ho ${ }^{32}$ cor de moltó ben levat en aygua tèbea; si u vol menyar, li serà molt bo ab lo sucra candi. E puys, dona-li a menyar carn de pola tendre o de colom novell, e no li dons molt a menyar en una veguada. E fe'l porguar per la bocha, per rahon de la fleuma que té en la bocha del ventreyll. Ages tres lerdons de carnselada grassa $a^{33}$ forme d'un dau gran, segons que

23 vulaveris] vulneris $\mathrm{JQ}$.

24 verboso] nerboso JQ.

25 claudil claudere JQ.

26 oli 0 oli ms.

27 neranills. namiths neranills ms.

28 a] $e \mathrm{~ms}$.

29 vaguades] vagudes $\mathrm{ms}$.

30 axi que] repetit ms.

31 E conexerets] repetit ms.

$32\{b o\}$ ms.

33 a] en JQ.

SCRIPTA, Revista internacional de literatura i cultura medieval i moderna, núm. 17 / juny 2021 / pp. 335 - 374 ISSN: 2340-4841 ·doi:10.7203/SCRIPTA.17.20916 


\section{Antoni Mas i Miralles. Tractat de medicina per tots els ocells de caça. Introducció, anàlisi lèxica i edició}

l'aucel ho porà soferir; puys, ages del pebre e de la sal, e mescla-u tot, mes sie més lo pebre ${ }^{34}$ que la sal, e anvolca-y los lardons bé e fort, e puys mit-los-li per la bocha bé pragon ab un fust. E mit-li desús un poch de aygua tèbee e garda que no ls git sempre. E porgar-s'à l'aucel fort e gitar-n'à tota la malenança de son ventre de la qual li ve lo vermis. [27r]

\section{A vermis}

Aquests lerdons deus donar a ton aucell almenys ${ }^{35}$ dues vaguades en l'any, en la antrada de muda e an la axida, quant serà bexat e aurà volat Xv dies o un mes. E són bons a fer gitar, e cure'ls set e tota malenança de cor d'aucel. Alcuns y mesclan sendre de sermens, mes no cal.

\section{A vormis o capvorm}

$\mathrm{Si} \mathrm{el}^{36}$ vormis o capverm és de fredor, dat-li mentegua e leyt de vaques o de ovelles. E, si conex que le metèrie sie digeste, fe-la-li gitar ab cobaràs, ço és, ab suc de sisagre ${ }^{37}$ o de pedro macedon que li mates per lo nars, e li’n fregaràs lo peladar. ${ }^{38}$ Ans que sie le matèrie digesta o medura, no la li deus fer gitar per res.

\section{Per porgar lo cap}

Per porgar lo cap, estafiagre ab leyt de fembre. ${ }^{39}$ Ítem, such de rayells de porros.

\section{Ítem. Per porgar lo ventre}

Suchs de cols verts ab sucra mesclat. ${ }^{40}[27 \mathrm{v}]$

\section{A pentayx}

Per a vòlfago, qui vol dir pentayx, si l'aucel deseque, met-li suc de cols per la gola, per grat o per força. Ítem, li és bone pólvere de reyells de cols ${ }^{41}$ cremades ab carn. Ítem, femta d'ome seca e molta, e hom li'n do ab la carn.

\footnotetext{
34 mes sie més lo pebre]-mas sie més to pebre mes sie mes lo pebre ms.

35 almenys] repetit ms.

36 el ell ms.

37 sisagre] fisagre JQ.

38 peladar pellador $\mathrm{ms}$.

39 fembre] mettes fembre ms.

40 Sucbs ... mesclat İtem, per porgar lo ventre, suchs de cols verts ab sucra mesclat JQ.

41 cols colls $\mathrm{ms}$.
}

SCRIPTA, Revista internacional de literatura i cultura medieval i moderna, núm. 17 / juny 2021 / pp. 335 - 374 


\section{Antoni Mas i Miralles. Tractat de medicina per tots els ocells de caça.} Introducció, anàlisi lèxica i edició

\section{Per pantaix}

Ítem, ages sanigrés e pansas e momie en una olla envernisada e bolits-ho tot; e, cant serà mitge, fets-ho bulir un poch més, e ab l'aygua banyats-li'n la carn que menya.

\section{A cascadura}

Per cascadura, prin momia e dona-li'n a menyar ab carn. Ítem, de la laor del moritort, qui val més. Ítem, encara és fort bone una erba qui ha nom rachaba, $\mathrm{e}^{42}$ aquella seca hom e fa'n hom pólvera e dona-li'n hom ab la carn.

\section{A crabantament, ço és, caschadura}

Astor, si és crebentat e tindrà son cap corp e aurà àvol alé e no's vol tost ardrial desexir de la mà, e açò que esmaltex és vert. E, cant aquest mal ha, dats-li a menyar un poch d'ancens ${ }^{43} \mathrm{o}$ de peònie $\mathrm{o}$ de diemargariton, en gise que ' $\mathrm{n}$ puscha pendre. $\mathrm{E}$, cant n'aurà menyat [e] açò abrà esmeltit dues o tres vaguades, prenets sament d'anet e fets-la bu-[28r]lir e, al vespre, dats-li'n un poch de leu de moltó beyat en aygua tèbee. E, si no guarex ab açò, dats-li'n a menyar poch dos dies e, al tercer die, dats-li mitge gorgua de moltó e, al vespre, dats-li un poch de moltó ho d'altre carn ab pólvere de gome aràbique. Ítem, li és bo segnar de las ungles a gran meravella, mas fa-li a continuar duos o tres dies, e, a matí e a vespre, la sagnie.

\section{De mudar aucells}

Cant volràs metre ton estor en muda, és ops que sie gras e porguat e que ${ }^{44}$ no aya polls. Porgar-lo deu hom deval e demont. E, quant conex hom que és ben gras e ben sans, deu-lo hom metre en la muda. E deu-li hom donar a menyar aytant com na vol, una vaguada lo jorn, ço és, a mitge tèrcie. E, segons que dien alcuns, no 1 deu hom fer benyar tro que ha mudat tots los coltells e los vans; mes puxes totes sepmanes una veguada. Mes verament aquests erran fort, car continuadamén, abans que git e quant ha gitat, ${ }^{45}$ lo deu hom benyar totes sepmanes una vaguada, e estan pus sa e [28v] milor ploma ne met e pus tost ne muda. E, si ss volien benyar tres o cotre veguades, ardidament se bany. E puys, fets-li metre devant una somada de arene gravillosa en què $s$ volch e mengerà de les pedres menudes, e curaran-lo molt.

\footnotetext{
42 e] e ell seca to ms.

43 ancens] acens JQ.

44 que] ge ms.

45 gitat gita ms.
} 
Ítem, mentre muderà, dats-li a menyar coloms o tortres, e pots-li dar le sepmane carn escorxadassa ${ }^{46}$ de moltó o de porch o de crestó. Les tortres, enperò, no li són bones si altre pots trovar, tro a la fin de juny. E, sobretot, és provat que val més son falcon mudat en perxa alte ${ }^{47} \mathrm{e}$ an loch escur. E deu-li hom hubrir les finestres de nit, que l'oreig hi entre. E és hops que no jage, que 1 jàser l'ascalfa lo fetga e li fa inflar los peus, e li fa porrets e gota; e no ss fer dels pits, s'anela e és-ne pus priuats. E, si 1 vols $^{48}$ cuytar de mudar, cant serà ben gras, dona-li gargamelles de moltó manut tellades, e donali glànoles de moltó del col o de les cuxes, e fets-li’n bone gorgua, e gardats que no s'i tingue altre carn. Ítem, li pots dar granotes vives ab altre carn mesclades, une veguada la setmane. Axí matex, li són bons aucels novels. Ítem, prenets un [29r] luert e fets-ne pólvere e, cant serà cremat, dona-li'n a menyar ab la carn. Ítem, bulits una serp en una olla ab molt forment, e puys dats aquel forment a menyar a coloms, e puys dats los coloms a menyar a l'aucel que volets tost ${ }^{49}$ mudar. Mas més val quant muden per lur temps.

\section{De trer aucell de muda}

Cant volràs traure ton aucell de muda, dona-li a menyar carn de pol, aytanta com ne vulla. E no 1 tragues $^{50}$ de la muda, si dons no s'enuge, entrò les plomes li sien crescudes per lur punt. E, con los aurets dat a menyar polls per tres setmanes o un mes, trets-lo de la muda e portats-lo matín e vespre, que no tingue gorgua. E, quant lo lexarets, metets-lo en loch escur. E, quant conexerets que les plomes seran axutes, donats-li a menyar cors de moltó remulat e de vaque e de vadel remulat, bones gorges. E dats-li polets petits ab la plome e ab tot.

\section{De bexar aucell}

Cant hom vol bexar son aucell, deu-lo hom bexar [29v] ab petites gorges, e podets lurs dar curals de plome ho de cotó dos ho tres vaguades le sepmane. Ítem, leu de moltó ben levat en aygua tèbea és bo per bexar son aucel. Ítem, dats-li sucre candi ab cors de moltó dos veguades le setmane. E, quant conexerets que sie ben bexat, fets-lo venir a la mà ho al loure de luny, en gise que en son volar él puscha sa carn baxà e pendre alent. E puys, cant farà fret, comensatslo a fer volar, e, si fa calor, no $l$ fasau volar sinó a matí e a vespre sens sol. E lavors fort poch lo feu trebeyllar per pahor ${ }^{51}$ de rompre son saguí. E fets-lo beyar aytantes veguades com se

46 escorxadassa] escorxadissa JQ.

47 alte] altre ms.

48 vols] vol ms.

49 tost tots ms.

50 tragues] tragres ms.

51 pahor] pehor ms.

SCRIPTA, Revista internacional de literatura i cultura medieval i moderna, núm. 17 / juny 2021 / pp. 335 - 374 ISSN: 2340-4841 $\cdot$ doi:10.7203/SCRIPTA.17.20916 
vulla, car aucel ce vol sovín benyar aprés la muda. E no vullats baxar aucel tost, com la meyor partida de la senitat de l'aucel se pren en l'axir de la muda car, si ell és bexat per ${ }^{52}$ son punt e ben nedeyat de dins, ell serà tot l'any delitós, si donchs altre accident no li ve. Cant lo bexerets e li aurets IIII o v gorges de carns corens donades, ço es, vadel, vaca o polls petits o leu de moltó, tot açò ben remullat; depuys podets-li dar une gorge de carn sustentive, ço es, carn de moltó calda o de galine grosa o de porch o de colom qui no sie masa veyll. Encara, quant volrets l'aucel alourar o clamar a la mà, devets gardar que l'aucel sie ben ardent e que l'alaurets a vespre e sus lo loure [30r] o sus la mà, si és aucel qui vinge a mà; e, quant serà vengut, no li donets ${ }^{53}$ àvol carn, mes bone e dolça sens benyar, per tal que pus volenterós vengua a la mà ho al loure. Sobre lo loure, negun temps no 'n donets sinó bone ho ${ }^{54}$ calde. Axí matex, quant ton aucell serà axit de muda, fe'l plomar e tirar sovén, car pus amorós ne será e profiterà-li a l'aygüe del cap.

Ab gorgua no deu hom fer plomar ni trebeylar son aucel. Si donques no-u feÿa, que no se'n pogués metre la gorge per algun accident, lavors lo fa hom plomar e à forces de metre le gorge. Mes açò no li u deu hom gayre tenir, mas adés adés un poch. Sobre tote res se deu quasedor ${ }^{55}$ esforcar de portar son aucel pla e ferm e segur, e que li sàpie seguir le mà als continens que son aucel ferà, que res no casque ten fort aucel com mal portar, meyorment en ${ }^{56}$ l'axir de la muda ho quant és aucell sor, mayorment nisayt. ${ }^{57}$

Les altres coses pertenens a 'queste matèrie és desots.

\section{D'engenramens de vèrmens}

Però porets seber que res no fa tant ne engendre [30v] vèrmens al cors de l'aucel com fa donar carns beyades ne aygoses. L'aucel, naturalment, deu aver vèrmens al cors per les carns crues que 's menge, qui són fleumàticas, de què s'engenren los vèrmens, e an açò s'ecorden los metges. E axí, si estar-te'n pots, no 'n dons a ton aucel carn beyada, si no ho fas a la axida de la muda. E, si li'n dones, exugue-le bé an un bel drap de li; puys, dona-la-li a menyar.

\section{De porgar aucells}

Si vols porguar ton aucel, da-li a menyar d'une pola afoguada, aytanta com ne volrà, ab plome e ab tot ansemps, e val molt. Probatum est.

52 per pe ms.

53 donets] donchs ms.

54 bo] be JQ.

55 quasedor] llegiu casador.

$56 e n] e \mathrm{~ms}$.

57 nisayt] llegiu nienc.

SCRIPTA, Revista internacional de literatura i cultura medieval i moderna, núm. 17 / juny 2021 / pp. 335 - 374 ISSN: 2340-4841 · doi:10.7203/SCRIPTA.17.20916 


\section{De colp d'uyll}

Si alcun aucel à pres colp an l'uyll, prenets de las plomes dels coloms noveylls e premets-les bé, e, d'equella sanch que n'exirà, metets-li'n an los vulls. E, axí matex, hi és bo vin blanch. Ítem, hi és bo que hom li mete femte de luert e ayguanafe e such d'escorxe de malgrane dolça que hom mastech en dejú; e aquest such, ab les altres coses, que li meta en l'uyll.

\section{De malaltie de frador}

Si alcun alcell ${ }^{58}$ és malaut de fredor, fets l'estar [31r] prop de brases, menys de fum. E, si açò no li val, dats-li a beure oli trucellí, e untats-li lo bech e les narius. E, ci açò no li val, dats-li crestiri ab est oli, e dats-li a menyar coloms, e dats-li primerament lo fetge.

\section{De maleutie de calor}

Si ha malautie de calor, metets-lo en fredor, en loch fret; e metets un poch de cànfer ${ }^{59}$ en aygüe frede e dats-li'n a beure un poch. E dats-li aygüe-ros ab un poch de sucre blanch, e gitats ${ }^{60}$ un poch d'oli violat mesclat $\mathrm{ab}$ aygüe-ros sobre $1 \mathrm{cap}$. E, quant lo lexerà la calor, dats-li a menyar coloms ho aucels novells.

\section{De hofeguament}

Per ofeguament e per posterma que age al ventre, no li do hom a menyar entrò que age nedeyat son ventre e son cors, e que sie clar ço que gitarà e no sie pudent. E prengua ${ }^{61}$ hom màstech e gingibre e alcaravia e canela, e fets-ne pólvere e gite'n sobre le carn que menyerà; e le carn sie de pol e ben axugada en un drap, e sie ben premuda. E, quant aurà gran fam, dats-li'n a menyar. E meta-lo ${ }^{62}$ hom en case lòbregua tro sie garit. He és-li bone pols ${ }^{63}$ de girofle. [31v]

\section{De gitar la gorgua}

Quant l'aucell gite ço que ha menyat, deu-lo hom afemar. E puys, do-li hom a menyar tres dies carn tendre ab pólvore de gingebre e de moritort e de canela. Lo primer die e lo segon die, dats-li carn de vaque; e lo terç die, dats-li'n carn de cabre. E cascune sie levada en aygua calda, e metets-hi pols ${ }^{64}$ de

\footnotetext{
58 alcell] alcells $\mathrm{ms}$.

59 cànfer] canser ms.

60 gitats] paraula esborrada; lectura dubtosa.

61 prengua] peprenga ms.

62 meta-lo] metaloto $\mathrm{ms}$.

63 pols] polchs ms.

64 pols] ptpols ms.
}

SCRIPTA, Revista internacional de literatura i cultura medieval i moderna, núm. 17 / juny 2021 / pp. 335 - 374 ISSN: 2340-4841 · doi:10.7203/SCRIPTA.17.20916 


\section{Antoni Mas i Miralles. Tractat de medicina per tots els ocells de caça.}

Introducció, anàlisi lèxica i edició

girofle. Encara crema hom de la cleda, e met-la ${ }^{65}$ hom en l'ayge cant és cremada, e lexats-la fondre e, puys, mulats le carn en aquella aygua.

\section{Per fleuma de ventreyll}

Per fleuma de ventreyll e de humors viscoses, deu-li hom dar vil grans de cabaràs a gran stor mudat, e a sor, $\mathrm{vI}^{66}$ grans, e a terçol, tres grans. E aquells picha hom bé e dona'ls hom a l'aucell ab le carn que menya. E, quant eurà gitada la fleume, doni-li hom a menyar d'un ${ }^{67}$ pol gras ho de galine negre.

\section{Quant clucla lus hulls}

Quant l'aucel clucha los vulls, deu-li hom metre oli musellí ${ }^{68}$ e mentegua de vaques, e de tot açò li dats a menyar ab la carn; e, al terç die, dats-li triaqua ab vi ho ${ }^{69}$ ab sendre ab vi. [32r]

\section{Quant l’aucel és fumat}

Si l'aucell és fumat, ${ }^{70}$ met-li hom e 1 nars oli violat ab let de fembre.

\section{De plagues}

Quant l'aucell ha plagues en les cames ho en altre loch, do-li hom orpiment vermeyll ab mel.

\section{De fístoles}

Quant l'aucell ha fístoles, dona-li hom a menyar retons pochs e mosteles novelles mulades en let de cabres, e, al cart die, mulades en oli. E mulats le gome en vinagre, e dats-li'n a menyar ab un pol gras.

\section{De ventusitat de gorgua}

Per ventusitat que l'aucel ha en la gorgua, prenets alfení e sucra blanch e fets-ne pólvere, e dats-li'n ab pols e ab aucells vius.

65 met-la] mettiti la ms.

66 VI] Hi ha una taca damunt de la segona xifra.

67 d'un] don ms.

68 Anteriorment havia escrit oli trucelli.

69 ho] ob ho ms.

70 fumat fumats $\mathrm{ms}$.

SCRIPTA, Revista internacional de literatura i cultura medieval i moderna, núm. 17 / juny 2021 / pp. 335 - 374 ISSN: 2340-4841 · doi:10.7203/SCRIPTA.17.20916 


\section{Quant no pot alenar}

Quant l'aucel ha enfoguament, que no pot alenar, prenets gome aràbiqua e diegargant, e fets-ho fondre en aygua, e metets-li de aquella aygua en la boque. E levats-li los caschavells e non casets, e dats-[32v]li momie ab oli sembassí. E, si açò no li val e aumagresque, dats-li a menjar let de vaques ab pebre lonch. E, ci aquel ofeguament és per fleume o per humós viscoses, prenets leborus album -solament lo cor de la reyell-, e picats-la e dats-li'n a menyar ab la carn, mes gordats ${ }^{71}$ que no li donets de la scorxa. E açò li dats ${ }^{72}$ ab mentegue e ab carn de galine. Ítem, prenets coloquianda ${ }^{73}$ [e] vert escur e salmoniach blanch e orpiment e gingebra, aytant de l'un com de l'altre, aytant com un siuró de cascú, e metets-hi sal negre, tant com mig siuró, e un gran de pebre, e picats-ho tot e fets-ho coure ab mantegua e ab aygua entrò sie axut. E puys, metets-ho an un drap e premets-ho bé e fets-ne tres parts, e, anans que li donets açò, donats-li a menjar un poch de mantegua frescha, e puys, dats-li açò demont dit, la una part la un die, e l'altre die l'altre part, e açò li dats ab galine negre o ab pol gras.

\section{De magrea}

Quant l'aucel és sobres magre, dats-li a menjar mentegua dos dies e, puys, hubrits-li la boque e metets-li tres gotes d'oli e de vinagre per le ger-[33r]guamella. E, al cort ${ }^{74}$ die, prenets un poch de vermayó e d'eleborus album, e adobats-ho ab mentegua, axí com ja us he dit en altre medecine, e metets-hi àloe ${ }^{75}$ e coloquianda, e prenets una rata novela e ascorxats-la bé, e masclats-hi d'equesta medicine tanta com porets levar ab una punta de coltell, ${ }^{76}$ e dats-li a menyar de bon moltó la hun die e, l'altre die, de un colom.

\section{Quant gite aygüe per los hulls}

Si l'aucell gite aygüe per los hulls, metets-li de la sanch de la hupegua en los huylls, ${ }^{77}$ e dats-li a menyar coloms ab sefrà, e tenits-lo en loch fosch. E, cascun mes, do-li hom una veguada la carn mulada en leyt de somera. E deus-li dar en yvern mel e an stiu, sucra a menjar ab carn.

71 gordats] llegiu guardats.

72 dats $]$ dat $\mathrm{ms}$.

73 coloquianda] quinada ms.

74 cort llegiu quart.

75 àloe] alooe ms.

76 coltell] coltell $\mathrm{ms}$.

77 buylls $]$ huylls ms.

SCRIPTA, Revista internacional de literatura i cultura medieval i moderna, núm. 17 / juny 2021 / pp. 335 - 374 ISSN: 2340-4841 · doi:10.7203/SCRIPTA.17.20916 


\section{De vent qui hix per lo nas}

Quant a l'aucell hix vent per lo nas, menys que no alena per la boqua, dats-li a menyar un poch de éloe e de castor, e fets-ne pólvera e dats-li'n a menyar. A cap de VII dies, prenets cendre de sermens e matets-le an aygua e, quant serà scla-[33v]rida, prenets de quella aygua e un poch de mel, e fets-ne pesses menudes de carn de moltó, e metets-les en alò e dats-li’n a menjar. E són-li bons coloms ab lo serveyl e ab los ossos.

\section{De gitar plomada}

Quant l'aucell té plomada en la gorgua e no la pot gitar, dats-li a menjar un poch de femne de porch ab gingebre ab la carn ensemps.

\section{De ventusitats de cos}

Quant l'aucell ha ventusitat de cos, conexerets aquesta malautie là un le aurà, que li u trobarets pus calt e, cant lo tocarets, veurets qu él se pleguarà e se'n farà squiu. Prenets un poch de jusquiam e metets-la an un drap ab una pessa de pulmó ${ }^{78}$ de moltó, he metets-hi un poch de mentegua e, tot ansemps, fets-ho bulir entrò sie cuyt. E puys, prenets-ho bé sobre un poch de mantegue e, quant serà fret, dats-li’n a menjar, axí com veurets que hops li sie. E, si ab açò no gorex, dats-li al such del jusquiam ab la carn a hora de mitdie, e fets-li boure de la aygua aquel die per tal que 1 such no l'auciés; e, l'endamà, dats-li pendre [34r] un poll ab la sanch e ab los budells, e lexats-li pendre de las plomes del pol que li darets a menyar.

\section{De dolor d'eschena}

Quant l'aucel ha dolor en l'esquena, ligats-lo sobre un fex d'erba vert, e aya sobre ell une quarabaça plene d'aygua, e fe-li al sol un forat poch, en guisa que l'aygua li caygua demont, sobre l'escane e $^{79}$ ab la mà ${ }^{80}$ adés adés. E dats-li a menyar carn mulada en oli. E fets bulir comí ab vi fort, e prenets un drap de feutre e mulats-lo an aquel vi, e posats-lo-li là unt aurà lo mal per dolor de la squena, e serà guarit.

\section{De dolor qui ve per veschositat}

Enperò si la dolor de l'asquene ve per veschositat, dats-li'n carn de pols ho de horonelles ab pólvera de gingibre e de batafalua, e no li do hom carn de galine. E prenets un poch d'oli de nous e de l'holi de remus, ${ }^{81}$ e dats-li'n ab carn de moltó, e no li donets molt a menjar. Ítem, si à ventusitat en les

\footnotetext{
78 pulmó] pultmo ms.

79 e] $e<$ entre les espatlles $i>$ JQ.

80 ab la ma] ab l'orina JQ.

81 oli de nous e de l'holi de remus] oli d'olives e de l'holi de nous JQ.
} 
ales, dats-li carn de pols mulada en oli d'emelles amargues, e gitats-hi desús pólvera de gingebre e de pólvera de canela e sucra blanch, e aminvats-li la vianda. [34v]

\section{De gota per tot}

Quant l'aucel ha gota per tot, prenets ${ }^{82}$ de la femna de las ovelles e fulles verdes de sàlzer e de totes les netures de murta de la fulla, e matets-ho tot an un vaxell de coura, e bula en ${ }^{83}$ aygua, en guisa que cobre les erbes entrò que le força de las erbes sie an l'aygua; e puys, prenets aquella aygua an un libreyll e posats-li un crivel desús. E, ${ }^{84}$ si no gorex d'eçò, dats-li a menyar carn de galine negre ab orpiment vermell, e metets-lo en loch lòbrech, e tocachs-lo ab la man desús en l'esquena, e valrà-li molt.

\section{A dolor de fetge}

A dolor de fetge, dats-li a menjar carn ab moritort blanch per tres dies, e serà garit.

\section{Per ventusitat}

Ítem, per ventusitat, li dats gingebre ab muritort.

\section{De vèrmens en la gorgua}

Ítem, quant l'aucell ha vèrmens en la gorgua, prenets un nap qui sie gros, e fets-hi un forat e umplits-lo d'aygua, e metets-lo al foch e, cant bulirà, prenets la carn e beyats-hi la carn an equella aygua, e dats-li'n a menjar. ${ }^{85} \mathrm{E}$ sie de moltó la carn.

\section{De vorm al ventre}

[35r] Quant l'aucel ha vormis e 1 ventre ho e ls budels, dats-li muritort blanch, e mulats le carn en vi de melgranes e, ci açò no val, mulats le carn en l'alquitrà.

\section{A pentax}

Si vols guarir sperver o altre hocell qui age pentayx ${ }^{86}$ prin le carn que li deus dar a menjar e mit-la en la horine calda, e lexe-y star le carn bone stone en la horine; e puys, trets-le'n e prim-la bé. E,

82 prenets] prenet $\mathrm{ms}$.

$83 \mathrm{en}]$ ten $\mathrm{ms}$.

$84 E]$ e <per aque el vapor després pugi envoltant-lo, poseu-bi l'ocell a sobre. I> JQ.

85 menjar mejar ms.

86 pentayx] la grafia $y$ está afegida.

SCRIPTA, Revista internacional de literatura i cultura medieval i moderna, núm. 17 / juny 2021 / pp. 335 - 374 
quant eçò euràs fet, prin fetme ${ }^{87}$ de hom qui sie ben secha e pica-la bé; e, quant serà bé picada, posa de la pólvere demont le carn que deu menyar, e continu-u de fer IX dies, e serà garit.

\section{D'ous d'asperver ho d'àls}

Quant l'esperver ho altre aucell és houat, prenets hortigues he picats-les bé; e, quant seran ben pichades, premets-les bé, e an lo such qui n'exirà beyats ben le carn que li devets dar a menyar; e, quant li auràs dat a menyar, posa'l sempre en una case ben scure, per tal que no senta l'oreyg, e açò continua de fer Ix dies.

\section{D’aygua de cap}

Quant l'asperver ha aygua al cap, prin ruda vert e, quant li deràs a menyar, ti ${ }^{88}$-la-li prop le carn, e axir-li-à l'aygua del cap. E, si ab açò no n'axia l'aygua, ayes cobaràs e pica'l bé e, quant serà ben molt, destempre'l $\mathrm{ab}$ let de fembre, e puxes cola-u tot ab un drap prim, e posa-li’n an los anerils, e garrà tantost. [35v]

\section{De càncer}

Quant l'asperver ha cànser en la bocha, prin una caneta e rau-li ${ }^{89}$ bé la bocha e lo peledar. E, quant açò auràs fet, mit-li encontinent arrop en la bocha, e garrà tantost.

\section{De smirladura}

Quant l'asperver no pot smirlar, prenets such de col e dats-li'n ab la carn a menjar. ${ }^{90} \mathrm{E}$, ci açò no val, dats-li such ab la carn e, ancontinent, esmirlarà.

\section{De porrets}

Quant l'asperver à porets en les mans, prenets nous veylles e such de mata e lart de porch veyll e cera nove, e tot açò pichats bé e, quant serà picat, ${ }^{91}$ destemprats-ho ab oli e posats-li’n tot dies en los porrets al sol; e ncontinent serà garit.

\section{De houament}

Quant l'esperver és houat, prenets oli e metets-lo en aygua e debatets-lo bé; e puys, l'escume qui n'exirà metets-la an una scudela, e puys, prenets la dita scudela e ab altre aygua batets-le bé, e puys, prenets l'ascume qui n'exirà e matets-la an una scudella; finalment pesats-la per v ayguades.

87 fetme] llegiu femta.

88 ti] $t i<n \mathrm{JQ}$.

89 rau-li] ti rau-li $\mathrm{ms}$.

90 menyar] meyar ms.

91 picat picats ms.

SCRIPTA, Revista internacional de literatura i cultura medieval i moderna, núm. 17 / juny 2021 / pp. 335 - 374 ISSN: 2340-4841 · doi:10.7203/SCRIPTA.17.20916 


\section{Antoni Mas i Miralles. Tractat de medicina per tots els ocells de caça.}

Introducció, anàlisi lèxica i edició

E, quant tot açò aureu fet, posa-la al sol e astige-y bone stone; e, quant deurets dar a menjar a l'asperver, untats-li'n le carn. [36r]

\section{De rodador}

Quant l'asperver es rodador, plomats-li les horelles en torn ho, si no, fets açò: cusits $^{92}$-li les plomes de la coa, e no roderà gens.

\section{De ronya ${ }^{93}$ de cans}

Quant lo ca és ronyós, prenets pedre marxe e argentviu e vinagre e tramentine e oli [e] blanquet cruu, e tot açò pichats bé, e ab oli destemprats-ho bé tot. E puys, untats lo ca ab aquestes coses demont dites.

\section{De ràbie de cans}

Quant lo ca és rabiós, prenets de las rayells dels porros, de v tro en VII, e pichats-las bé e metets-las bé en oli, en guise que s'i cobren, e astiguen axí un die e una nit, que no menyg. ${ }^{94} \mathrm{E}$ puys, ayats un poch de pa esmicolat e masclats-lo ab aquelò. E puys, dats-ho a menjar al ca. E fets açò tres dies, e axí guarà si jamés deu guarir.

\section{Infladure de cames}

Quant l'aucel ha inflades les cames ho les mans per artèticha, fenets-li $\mathrm{ab}^{95}$ vidre tayant là unt aurà imflat. E puys, prenets un poch de àloe e de goma aràbique e de blanch d'ou e de safrà, e picats ço que fa a picar, e mesclats-ho ab lo blanch d'ou, e metets-ho tot an un test e mesclats-ho tot sobre 1 foch e posats-li-u sobre 1 [36v] mal. E, si no gorex ab açò, cramats-li-ho ab fust de mirtre.

\section{Ítem, a infladura e durícia en les guntures de les mans dels aucels ${ }^{96}$}

Aver armuriach e galbanum disolts en vinagre, e sia'n fet enpastre ab aluda, e sia mès sobre lo loch inflat. ${ }^{97}$

92 cusits] cusitstrisi ms.

93 ronya] roya $\mathrm{JQ}$.

94 menyg] llegiu meng.

$95 a b]$ apareix afegida.

96 JQ trasllada aquest fragment a l'apèndix, on apareixen els apartats escrits per una altra mà.

97 Ítem ... inflat] Aquest apunt apareix al marge inferior del foli 36r i està escrit amb una altra mà. 


\section{De mal de cuxa}

Quant l'aucel ha axida ho gitada la cuxa del loch ho altres ${ }^{98}$ trancaduras, fets molra un poch d'encens e de sanch de dragó, e pichats-ho ab vinagre, e posats-ho sobre drap de li, e posats-li-u sobre là unt aurà le trancadura, e ligau-li-u en guisa que no li fassa mal.

\section{De poys}

Quant l'aucel ha poys, prenets del leborum album e tranchats-lo, e astreyets-li'n les mans. E fets bulir coloquianda en aygua e, quant sie refredada, beniats-lo. Ho ajats aygüe en què aye bulit sinigrech, ${ }^{99}$ e puys, beyats-lo'n desús les ales ab la bocha. Ho y fets bulir sencòniga, ${ }^{100}$ ço és erba lumbriguera, e bayats-lo-y.

\section{Per arencament de plomes}

Quant l'aucel s'erancha les plomes, dats-li a menjar alfaní ab girofle e ab melce de moltó tres dies. E puys, prenets un rave e trocats-lo e humplits-lo de mantegua, e fets-lo bulir sobre $1 \mathrm{l}$ foch. E, quant serà fret, dats-li a menjar de la mantegua. E ajats àloe e safrà e ab alisiom untats-li les mans e les cames e les plomes. E, si no’s lexa de plomar, untats-li les [37r] mans e les cames ab fel de moltó.

\section{De menyament de plomes}

Quant l'aucel ce menye les plomes, prenets un poch de safrà he orpiment e fets-ho molre, e puys, bulir, e pastats-ho ab oli, he untats-li les plomes.

\section{De vèrmens en les plomes}

Quant se fan vèrmens en les rayels de las ${ }^{101}$ plomes, fanets-li les rayells e trets-li'n un nuu redon qui ss fa dins, e puys, complits-los-li d'orpiment pastat ab vi.

\section{D'erancament de plomes}

Quant l'aucell s'erancha les plomes, untats les raels de las plomes ab oli e ab vinagra, e levats-li-u $\mathrm{ab}$ aygua calda.

\section{De palament de col}

Quant l'aucel se pela lo col e al cap e les ales, untats-li là unt se plome ab oli rossat.

98 altres] altre $\mathrm{ms}$.

99 sinigrech] finigrech $\mathrm{JQ}$.

100 sencòniga] sentòniga JQ.

101 rayels de las] apareixen interlineats. 


\section{Antoni Mas i Miralles. Tractat de medicina per tots els ocells de caça. Introducció, anàlisi lèxica i edició}

\section{De bexament de cap}

Quant veureu bexar lo cap a vostre aucel, e les vulls li tornen grochs e negres mesclats, e que no s secuda tan bé $\operatorname{com}^{102}$ sol, e que no stigua en un peu axí com sol, prenets de la peònie lo pes de un millarès, $[37 \mathrm{v}]$ e sie ben picada. E prenets carn calda, lo pes de dues nous, e ab aquella pólvera dats-li a menjar, e tenits-lo en la mà tro age pasada la gorgua; e puys, bulits sament d'api en aygua e, quant serà freda, posats-la-li denant si s volrà beyar. E, si ab açò no gorex, dats-li a menjar galine negre e que begua de la sanch. E, si no guarex, prenets un poch de pólvera d'ansens, ${ }^{103}$ e ab tanta de carn com dues nous dats-la-li a menjar, e tenits-lo tant tro que pex ${ }^{104}$ blanch $^{105}$ e, quant sie migdie pessat, posats-li l'aygua denant que ja avem dita e, a la nit, dats-li gorgua de moltó.

\section{De retenir la plomada}

Quant l'aucell reté la plomada, que no la gita, dats-li a menyar segín de porch ab pólvere de gingibre.

\section{A una malaltie que ha nom sterami}

E açò conexerets quant l'aucel starà enfusteguat en la mà, ço és, que starà tot dur e no 's volrà partir del puny, e alò que gitarà, quant tirarà, ${ }^{106}$ retirarà a verdor, e la negror que y fa no plegua a cap de la tirada, ${ }^{107}$ ans stà al mig loch, e és pus alt que tot l'àls. E veurets que menge la carn ab gran talent, e pren les bocades menudes, e no ss sedole de menjar. E aytal melautie ha l'aucel pus fort a la part dreta, endret [38r] del fetge ho de la part hon més li penge l'ala. E, quant hom li vol dresar l'ala, és-li greu.

\section{És aquesta la cure}

Per aquesta malaltie fets aytal cure: dats-li a menjar pólvera d'ensens ${ }^{108}$ ab tanta carn com tres nous, e tenits-lo tant en la mà tro que tir; ${ }^{109} \mathrm{e}, \mathrm{com}$ sien pessades tres hores del die, fets coure del ${ }^{110}$ pes

$102 \mathrm{com}] \cos \mathrm{ms}$.

103 ansens] asens JQ.

104 pex] pexx ms.

105 pex blanch] esmaltesch JQ.

106 Tot i que el text subratlla el mot tirarà, el restituïm per donar-li sentit a l'oració, ja que es tracta clarament d'una correcció inapropiada.

107 tirada] tirata tirada $\mathrm{ms}$.

108 ensens] esens JQ.

109 tin tir $<$ tres vegades $>$ JQ.

110 del de $<$ a sentòniga, és a dir, de l'herba llombriguera $>\mathrm{JQ}$. 
de dos milaresos, e bulits-lo en aygua e lexats-la refredar, e posats-la en loch un se puxa banyar; e la nit dats-li a menjar carn de galine ab la sanch sue. E, si no guarex, prenets lo pes de mig milars de penís e atretant de sement de muritort qui sie pichat e, al matí, dats-li a menjar tot açò ab tanta carn com tres nous; e, com sie migdie pasat, dats-li del leu del moltó, tant com menjar ne vulla.

\section{Altre malaltia que hom apella gits}

$\mathrm{E}^{111}$ conexerets-le con tindrà la care inflada e à los vulls plens d'aygua, e vol perxar e no ha què, e açò que gita és rodon e pres, axí con gran de malgrane, e grate's lo coll e astà cuytós de perxar. A tal malaltie fets-hi aytal cura: prenets holi e vinagre e fil e bòrach ${ }^{112}$ e mel e aygua de serment e leyt de vaque, aytant d'un com d'altre, e del fel de la ovella dos tans que la una de las coses desús dites, ${ }^{113}$ e pi-[38v]cat e destemprat tot, fets-li'n crastiri ab une plome, axí com se tany de fer; e puys, datsli a menjar tres pesetes de carn grasse ab un poch de sal e de mentegue; e, quant açò age menjat, metets-li en la boque un poch de let de fembre ho aygua freda; e picats-hi sucre, tant que torn axí com a serveyl, e mulats-ho ab aygua, e dats-li-u a menjar per dos ho tres dies arreu.

\section{De dar viandes}

Totes coses que vulau dar a osell, si no les vol pendra per si, podeu-les-li dar ab carn ho alcun budelet.

\section{Per desfici}

Quant l'aucel ha desfici, conexerets-ho quant lo vaurets molt splugar e 's grata fort, e assò ss farà stant en la sue força, e menja molt e no pot engruxar, e cascun die crex la sue sechadat, e an açò que gitarà veurets unes venes vermelles.

A tal malaltie ${ }^{114}$ dats una pocha de peònia ${ }^{115}$ ben pichada ab tanta carn com dues nous, e, quant tres hores del die seran pessades, posats-li de la aygua devant, e puys, dats-li a menjar tanta carn de moltó com un ou. [39r] E, si ab acò no gorex, dats-li porcel prou a menyar.

\section{De febre e de dolor}

Quant l'aucel ha febre ho dolor al cap per fleume, conexerets-ho quant age al cap inflat e les nerills li stanquen e crex-li l'aygua als vulls e perxe sovén.

111 E] E altre malaltia que hom apella gits JQ.

112 bòrach] orach $\mathrm{ms}$.

113 que la una de las coses desús dites] Sembla que la frase està incompleta.

114 malaltie] malltie ms.

115 peònia] penia ms.

SCRIPTA, Revista internacional de literatura i cultura medieval i moderna, núm. 17 / juny 2021 / pp. 335 - 374 


\section{Antoni Mas i Miralles. Tractat de medicina per tots els ocells de caça.}

Introducció, anàlisi lèxica i edició

\section{La cura és aquesta}

Cura a tal malaltie: prenets cabarràs e sal blanque, e palats-li les narils e matets-li d'eçò. Ajats melgranes dolces e del cabarràs e, ab lo dit, fragats-li lo paladar, ${ }^{116}$ e puys, mostrats-li l'aygua freda entra tèrcia e migdie, e puys, dats-li'n de calda entrò ora de nona; e puys, dats-li’n a menjar galine negre.

\section{De fleuma}

Quant l'aucel ha fleuma, conaxerets-ho cont menge molt e tost, e li cruxirà la gargamella e se'n matrà la carn ensemps.

\section{La cura}

Cura ha aytal malaltie: prenets un poch de vidra e pichats-lo bé e mulats-hi un poch de carn de moltó an oli rosat, e ab la pólvera del vidre dats-li a menjar. E, si ab açò no gorex, prenets lo pes de [39v] mig milars ${ }^{117}$ e atretant de reel ${ }^{118}$ nemoran, e pichats-lo ab mel, e dats-li-u ab cuxa de galine.

\section{De barraam}

Quant l'aucel ha una melaltie que apella hom baraam, e ve per fum ho per poys ${ }^{119}$ ho per rosada, açò conexerets que ls corre aygua per les narils e, quant vol piular, no pot, qu és ronch e, quant se vol debatre, pren-li afogament.

\section{La cura}

Cura ha aytal malautie: prenets dos grans de cobarràs e un poch de grane de mostalla e un poch de pebre lonch, e de cascun pes d'un millarès, e picats-ho ben, e puys, ayats mel bulida e mel scumada, e mesclats-ho bé ab aquesta mel; e puys, ajats un drap de li e prenets açò ab aquel drap, e fragats-li'n lo peladar e tota la bocha. E puys, posats-li devant aygua tèbee, sol un poch, e puys, pexets-lo de galina negre e begua de la sanch.

\section{De sentidura d'ales}

Quant l'aucel ha centidure d'ales, ajats urine de infant e gitats-li'n en les ales, e açò fets tres dies. E, si açò no 1 gorex, prenets un poch de paylla de forment e fets-la bulir en aygua, e puys, matets-la an un colador, ${ }^{120}$ e fets-la-li caura desús les ales, e levats-li'n [40r] là unt aurà mal ab aquesta aygua

\footnotetext{
116 paladar palador ms.

117 milars] milars < de sal amoniac $>$ JQ.

118 de reel] de $($ reel $<$ de> $)$ JQ.

119 poys pols JQ.

120 colador] colador ms.
} 
tèbea; e puys, sacnats-lo desots l'ale en aquela vene groça antrò que n'isquen x gotes de sanch, e puys, levats-la-y ab aygua freda; ${ }^{121}$ e puys, prenets un poch de sal ${ }^{122}$ e un poch d'oli e mesclats-ho, e puys, prenets un poch de lane e mulats-la an açò e posats-la-li en la sacnia; e puys, posats-lo en case lòbregua e astigua axí une sepmane, e dats-li carn de moltó e beyats-la-li a veguades ab la dita aygua, e sie tèbea.

\section{De menyança}

Quant l'aucel ha une melautie que apella hom menjança, ço és, quant s'eranquen les plomes e tenenles al bech e no les vol gitar e, quant les gite, troba-les hom que són menjades en la rayel e sangonosses.

\section{La cura és aytal}

Cura ha aytal malautia: prenets del vinagre e levats-li'n là un aja lo mal, e conexarets-ho per imflament de la cara. Prenets dels renchs dels ${ }^{123}$ bous qui ss tenen als bous ho a les vachas, e metetslos en vinagre forts, e astigan-i tant tro que 1 vinagre sia sech, e picats los renchs lo pes [40v] de un diner ab aytant de nou cremada, e pestats-ho tot ab oli e untats-li'n aquells lochs, e fets açò per tres dies entrò que vayats que les plomes de quel loch cresquen e sien forts. E, ci açò no-y val, prenets l'aucel e beyats lo tot ab vinagre, del cap enfore, e segnats-lo en la vene grosa dejús le ala, axí com ja demont avem dit; e prenets un poch de bon $\operatorname{arap}^{124}$ e, ab del vinagre, untats-li'n aquels lochs; e prenets pa de forment e mengau-lo, ${ }^{125}$ e de aquella pólvera prenets pes de un millars e dos tans d'orpiment e pes ${ }^{126}$ d'un milars d'escorxa de malgranes dolces, e de tot açò fets pólvera e posats-lali là unt aurà lo mal, e dats-la-li a menjar carn de moltó ab mel.

\section{De sagnar}

Le milor medecine que aquesta malaltie ${ }^{127}$ és qui bé sab fer sagnar a l'aucell desots l'ala, sobre la cuxa de la part dreta; e, quant serà uberta aquela vene, prenets una pocha d'elcana e mentegua de vaques, e mesclats-ho tot he untats-lo'n an aquel loch unt és le sannia, e puys, dats-li a menjar carn de moltó, bona gorgua.

\footnotetext{
121 freda] tebea freda $\mathrm{ms}$.

122 sal sall ms.

123 dels del ms.

124 arap] borac armeni JQ.

125 mengeu-lo] cremats-lo JQ.

126 pes] pers ms.

127 malaltie matitute quit malaltie $\mathrm{ms}$.
} 


\section{Antoni Mas i Miralles. Tractat de medicina per tots els ocells de caça. Introducció, anàlisi lèxica i edició}

\section{De menjança}

Quant l'aucel ha aquesta menjança, prenets cobarràs ab la croste e pichats-lo, e metets-lo an un [41r] drap a remular en aygua freda e, si és en ivern, en calda; e ab aquel drap fragats-li lo peledar e la boqua tres veguades al die, e puys posats-lo en la perxa e astigua tant tro esmoltesqua.

\section{De flaquea e fa semblant de mort}

Quant l'aucel és flach e fa semblant de mort, prenets tant com un hou de bone mentegua de vaques, e matets-li'n en la gargamela, e axí sforçar-s’à. E puys, no 'n menyg tro al mitgdie, e que s'espluch e que 's sacuda. E puys, dats-li a menyar pol gras ho colom novel e, quant l'auciràs, gardats que no n'isque le sanch, e dats-li'n a menjar quaucom de la sanch e dels hosos. ${ }^{128}$

\section{Per ocel que sia cascat}

Per ocel cascat auràs pólvora de be mesué, ${ }^{129}$ e d'aquella li daràs ab la carn tres voltes la semana o més. Re més, ${ }^{130}$ a ton arbitre.

\section{Ítem, ocel que aga ayga al cap}

Pren momia, tant com hun ciuró. Ítem, salònia, altretant. Ítem, cendra de sarments, altretant. Ítem, pebre he oruga, de quada hu altretant. E tot polveritzat ab tanta mel com mija avelana ne sia feta huna $[\ldots] \cdot[41 \mathrm{v}]$

\section{Per pantax}

Aver mantega e dar-ne ab la carn tan com huna castaya. És bona per lo pantax e ngruxa l'ocel.

\section{Per lo dit pantax}

Aver riubàrber e raureu hun poc, en cantitat d'una lentila, en aygua d'endivia, e fer-l'estar tota la nit a l'ayre. ${ }^{131} \mathrm{E}$ la cantitat de la aygua sia tanta com miga closca d'ou e queucom més; e aprés, al péxer, mular la carn.

\footnotetext{
128 hosos] hosors $\mathrm{ms}$.

129 be mesue] bemestue be mesue ms.

130 Re més] sen reemes ms.

131 l'ayre] la serena JQ.
} 


\section{Antoni Mas i Miralles. Tractat de medicina per tots els ocells de caça.}

Introducció, anàlisi lèxica i edició

\section{Quant l'aucell té la mà ${ }^{132}$ inflat per colp}

Aver apopònach, bedeli, gàlbanum, he tot mesclat fer-ne enpastre en aluda e metre-u sobre lo peu.

\section{Més per infladura, he és lo milor que s'i pot fer}

Aver raels de carabacins e fer-ne aygua ab alambí, e de la dita aygua, ab cotó, que y sia remullat, e aprés enbolicat lo dit cotó mulat en l'aygua en la mà de l'ocel, e guarà indubtadament, e, quant la mà serà desinflada $[\ldots]$.

$132 \mathrm{ma}]$ per ma ms.

SCRIPTA, Revista internacional de literatura i cultura medieval i moderna, núm. 17 / juny 2021 / pp. 335 - 374 ISSN: 2340-4841 · doi:10.7203/SCRIPTA.17.20916 